\title{
Soft points, $s$-relations and soft rough approximate operations
}

\author{
Guangji Yu* \\ School of Information and Statistics, Guangxi University of Finance and Economics, Nanning, Guangxi \\ 530003, P.R.China \\ E-mail: guangjiyu100@126.com
}

Received 8 October 2014

Accepted 2 September 2016

\begin{abstract}
Soft set theory is a new mathematical tool to deal with uncertain problems. Since soft sets are defined by mappings and they lack "points", managing them is not convenient. In this paper, the concept of soft points is introduced and the relationship between soft points and soft sets is investigated. We prove that soft sets can be translated into soft point sets and may be expediently handled like ordinary sets. Moreover, we propose $s$-relations on soft sets. By means of soft points and these results, a pair of soft rough approximate operations is defined. Serial, reflexive, symmetric, transitive and Euclidean $s$-relations are characterized by using soft rough approximate operations. In addition, we research soft topologies induced by a reflexive $s$-relation on a special soft set and gives their structure.
\end{abstract}

Keywords: Soft sets; Soft points; Soft point sets; s-relations; Soft rough approximate operations; Soft topologies.

\section{Introduction}

Most of traditional methods for formal modeling, reasoning and computing are crisp, deterministic and precise in character. However, many practical problems within fields such as economics, engineering, environmental science, medical science and social sciences involve data that contain uncertainties. We cannot use traditional methods because of various types of uncertainties present in these problems.

There are several theories: probability theory, fuzzy set theory ${ }^{27}$, interval mathematics, and rough set theory ${ }^{22}$, which we can consider as mathematical tools for dealing with uncertainties. But all these theories have their own difficulties (see ${ }^{21}$ ). For example, probability theory can deal only with stochastically stable phenomena. To overcome these kinds of difficulties, Molodtsov ${ }^{21}$ proposed a completely new approach, which is called soft set theory, for modeling uncertainty.

Presently, works on soft set theory are progressing rapidly. Maji et al. ${ }^{18,20,19}$ further studied soft set theory, used this theory to solve decision making problems and devoted fuzzy soft sets combining soft sets with fuzzy sets. Roy et al. ${ }^{24}$ presented a fuzzy soft set theoretic approach towards decision making problems. Li et al. ${ }^{12}$ investigated decision making based on intuitionistic fuzzy soft sets. Jiang et al. ${ }^{10}$ extended soft sets with description logics. Aktas et al. ${ }^{2}$ defined soft groups. Li et al. ${ }^{16}$ proposed $L$ fuzzy soft sets based on complete Boolean lattices. Feng et al. ${ }^{6,7}$ investigated the relationship among soft sets, rough sets and fuzzy sets. Ge et al. ${ }^{8}$ discussed relationships between soft sets and topologi-

\footnotetext{
* Corresponding author: Guangji Yu
} 
cal spaces. Shabir et al. ${ }^{25}$ proposed soft topological spaces which are defined on the universe with a fixed set of parameters. Babitha et al. ${ }^{5}$ introduced relations on soft sets. Li et al. ${ }^{13,14}$ considered roughness of fuzzy soft sets and obtained the relationship among soft sets, soft rough sets and topologies. Li et al. ${ }^{15}$ studied parameter reductions of soft coverings.

Rough set theory was proposed by Pawlak ${ }^{22}$. It is an extension of set theory for the study of intelligent systems characterized by insufficient and incomplete information. The foundation of its object classification is an equivalence relation. The upper and lower approximation operations are two core notions in rough set theory. They can also be seen as a closure operator and an interior operator of the topology induced by an equivalence relation on a universe. We may relax equivalence relations so that rough set theory is able to solve more complicated problems in practice. Pawlak rough set theory has been extended to tolerance relations, similarity relations, binary relations $17,26,30$.

Since soft sets are defined by mappings and then lack "points", managing them is not convenient. Thus, we try to attempt introducing the concept of "soft points" and deal with them as same as ordinary sets.

Feng et al. ${ }^{7}$ proposed soft rough approximate operations. But the introduction of these operations seemed suddenly and disposing them is not convenient as soft sets lacks "points" and "soft points" are not proposed. In this paper, we introduce the concept of soft points, prove that soft sets can be translate into soft point sets and then it is convenient to deal with soft sets as same as ordinary sets. We propose $s$-relations on soft sets. By means of soft points and these results, soft rough approximate operations are defined. And because we do the above work, it is very convenient to deal with the operations introduced by us.

The organization of this paper is as follows: In Section 2,we briefly recall basic concepts about rough sets, soft sets and soft topological spaces. In Section 3, we introduce the concept of soft points and investigate the relationship between soft points and soft sets. In Section 4, we introduce the concepts of serial, reflexive, symmetric, transitive and
Euclidean $s$-relations on soft sets, and investigate the relationships between these $s$-relations and soft point sets. In Section 5, we propose two soft rough approximate operations. In Section 6, we investigate soft topologies induced by a reflexive $s$-relation on a special soft set and give their structure. Section 7 concludes this paper and highlights the prospects for potential future development.

\section{Overview of rough sets, soft sets and soft topological spaces}

In this section, we briefly recall basic concepts about rough sets, soft sets and soft topological spaces.

Throughout this paper, $U$ refers to an initial universe, $E$ refers to the set of parameters and $2^{U}$ denotes the power set of $U$. We only consider the case where both $U$ and $E$ are nonempty finite sets.

\subsection{Rough sets}

Let $R$ be an equivalence relation on $U$. The pair $(U, R)$ is called a Pawlak approximation space. Using the equivalence relation $R$, one can define the following rough approximations:

$$
\begin{aligned}
& R_{*}(X)=\left\{x \in U:[x]_{R} \subseteq X\right\}, \\
& R^{*}(X)=\left\{x \in U:[x]_{R} \cap X \neq \emptyset\right\} .
\end{aligned}
$$

Then $R_{*}(X)$ and $R^{*}(X)$ called the Pawlak lower approximation and the Pawlak upper approximation of $X$, respectively.

The Pawlak boundary region of $X$, defined by the difference between these Pawlak rough approximations, that is $B n d_{R}(X)=R^{*}(X)-R_{*}(X)$. It can easily be seen that $R_{*}(X) \subseteq X \subseteq R^{*}(X)$.

A set is Pawlak rough if its boundary region is not empty. Otherwise, the set is crisp. Thus $X$ is Pawlak rough if $R_{*}(X) \neq R^{*}(X)$.

We may relax equivalence relations so that rough set theory is able to solve more complicated problems in practice. Pawlak rough set theory has been extended to binary relations $17,26,30$.

Definition $2.1\left({ }^{30}\right)$ Let $R$ be a binary relation on $U$. The pair $(U, R)$ is called a approximation space. Based on the approximation space $(U, R)$, we define a pair of operations $\underline{R}, \bar{R}: 2^{U} \longrightarrow 2^{U}$ as follows: 


$$
\begin{aligned}
R & (X)=\{x \in U: R(x) \subseteq X\}, \\
\bar{R}(X) & =\{x \in U: R(x) \cap X \neq \emptyset\},
\end{aligned}
$$

where $X \in 2^{U}$ and $R(x)=\{y \in U: x R y\}$ is the successor neighborhood of $x$. Then $\underline{R}(X)$ and $\bar{R}(X)$ are called the lower approximation and the upper approximation of $X$, respectively.

$X$ is called a definable set if $\underline{R}(X)=\bar{R}(X) ; X$ is called a rough set if $\underline{R}(X) \neq \bar{R}(X)$.

\subsection{Soft sets}

Definition 2.2 $\left({ }^{21}\right)$ Let $A \subseteq E . \quad A$ pair $(f, A)$ is called a soft set over $U$, if $f$ is a mapping given by $f: A \rightarrow 2^{U}$. We denote $(f, A)$ by $f_{A}$.

In other words, a soft set over $U$ is the parameterized family of subsets of the universe $U$. For $\varepsilon \in A$, $f(\varepsilon)$ may be considered as the set of $\varepsilon$-approximate elements of the soft set $f_{A}$. Obviously, a soft set is not a ordinary set.

Denote $S(U, E)=\left\{f_{E}: f_{E}\right.$ is a soft set over $\left.U\right\}$.

Definition 2.3 $\left({ }^{18}\right)$ Let $A, B \subseteq E, f_{A} \in S(U, A)$ and $g_{B} \in S(U, B)$.

(1) $f_{A}$ is called a soft subset of $g_{B}$, if $A \subseteq B$ and $\forall \varepsilon \in A, f(\varepsilon) \subseteq g(\varepsilon)$. We write $f_{A} \widetilde{\subset} g_{B}$.

(2) $f_{A}$ is called a soft super set of $g_{B}$, if $g_{B} \widetilde{\subset} f_{A}$. We write $f_{A} \widetilde{\supset} g_{B}$.

(3) $f_{A}$ and $g_{B}$ are called soft equal, if $A=B$ and $\forall \varepsilon \in A, f(\varepsilon)=g(\varepsilon)$. We write $f_{A}=g_{B}$. $f_{A} \widetilde{\supset} g_{B}$.

Obviously, $f_{A}=g_{B}$ if and only if $f_{A} \widetilde{\subset} g_{B}$ and

Definition $2.4\left({ }^{3},{ }^{18}\right)$ Let $A, B \subseteq E, f_{A} \in S(U, A)$ and $g_{B} \in S(U, B)$.

(1) $h_{A \cup B}$ is called the union of $f_{A}$ and $g_{B}$, if

$$
h(\varepsilon)= \begin{cases}f(\varepsilon), & \text { if } \varepsilon \in A-B, \\ g(\varepsilon), & \text { if } \varepsilon \in B-A, \\ f(\varepsilon) \cup g(\varepsilon), & \text { if } \varepsilon \in A \cap B\end{cases}
$$

We write $f_{A} \widetilde{\cup} g_{B}=h_{A \cup B}$.

(2) $h_{A \cap B}$ is called the soft intersection of $f_{A}$ and $g_{B}$, if $\forall \varepsilon \in A \cap B, h(\varepsilon)=f(\varepsilon) \cap g(\varepsilon)$. We write $f_{A} \widetilde{\cap} g_{B}=h_{A \cap B}$.
Remark 2.5 Let $A, B, C \subseteq E, f_{A} \in S(U, A), g_{B} \in$ $S(U, B)$ and $h_{C} \in S(U, C)$. Then

(1) $f_{A} \widetilde{\cap} g_{B} \widetilde{\subset} f_{A}\left(\right.$ or $\left.g_{B}\right) \widetilde{\subset} f_{A} \widetilde{\cup} g_{B}$.

(2) If $h_{C} \widetilde{\subset} f_{A}$ and $h_{C} \widetilde{\subset} g_{B}$, then $h_{C} \widetilde{\subset} f_{A} \widetilde{\cap} g_{B}$.

(3) If $h_{C} \widetilde{\supset} f_{A}$ and $h_{C} \widetilde{\supset} g_{B}$, then $h_{C} \widetilde{\supset} f_{A} \widetilde{\cup} g_{B}$.

Definition 2.6 $\left({ }^{25}\right)$ Let $A \subseteq E, f_{A}, g_{A}, h_{A} \in S(U, A)$. $h_{A}$ is called the difference of $f_{A}$ and $g_{A}$, if $\forall \varepsilon \in A$, $h(\varepsilon)=f(\varepsilon)-g(\varepsilon)$. We write $h_{A}=f_{A}-g_{A}$.

Definition $2.7\left(^{3}\right)$ Let $A \subseteq E, f_{A}, g_{A} \in S(U, A) . g_{A}$ is called the relative complement of $f_{A}$, if $\forall \varepsilon \in A$, $g(\varepsilon)=U-f(\varepsilon)$. We write $g_{A}=f_{A}^{\prime}$ or $\left(f_{A}\right)^{\prime}$.

Proposition 2.8 $\left(^{3}\right)$ Let $A \subseteq E, f_{A}, g_{A} \in S(U, A)$. Then

(1) $\left(f_{A} \widetilde{\cup} g_{A}\right)^{\prime}=f_{A}^{\prime} \widetilde{\cap} g_{A}^{\prime}$.

(2) $\left(f_{A} \widetilde{\cap} g_{A}\right)^{\prime}=f_{A}^{\prime} \widetilde{\cup} g_{A}^{\prime}$.

Remark 2.9 Let $A \subseteq E, f_{A}, g_{A} \in S(U, A)$. Then

(1) $\left(f_{A}^{\prime}\right)^{\prime}=f_{A}$.

(2) $f_{A} \widetilde{\subset} g_{A} \Longleftrightarrow\left(f_{A}\right)^{\prime} \widetilde{\supset}\left(g_{A}\right)^{\prime}$.

Definition 2.10 $\left({ }^{25}\right)$ Let $X \in 2^{U}$. The soft set $X_{E}$ over $U$ is defined by $\forall \varepsilon \in E, X(\varepsilon)=X$.

In this paper, $U_{E}$ and $\emptyset_{E}$ are also denoted by $\widetilde{U}$ and $\widetilde{\emptyset}$, respectively.

Remark 2.11 Let $f_{A}, g_{A} \in S(U, A)$. Then

(1) $U_{A}-f_{A}=f_{A}^{\prime}$,

(2) $f_{A} \widetilde{\cap} g_{A}=\emptyset_{A} \Longleftrightarrow f_{A} \widetilde{\subset} g_{A}^{\prime}$,

(3) $f_{A}-g_{A}=f_{A} \widetilde{\cap} g_{A}^{\prime}$.

\subsection{Soft topological spaces}

In what follows we consider problems on the universe $U$ and the fixed set $E$ of parameters.

Definition 2.12 $\left({ }^{25}\right) \tau \subseteq S(U, E)$ is called a soft topology over $U$, if $(i) \widetilde{\emptyset}, \widetilde{U} \in \tau$; (ii) the union of any number of soft sets in $\tau$ belongs to $\tau$; (iii) the intersection of any two soft sets in $\tau$ belongs to $\tau$.

The triplet $(U, \tau, E)$ is called a soft topological space over $U$. Every element of $\tau$ is called a soft open set in $U$ and its relative complement is called a soft closed set in $U$. 
In this paper, the family of all soft closed sets is denoted by $\tau^{\prime}$.

Definition $2.13\left({ }^{25}\right)$ Let $(U, \tau, E)$ be a soft topological space over $U . \forall f_{E} \in S(U, E)$, the soft closure of $f_{E}$ is defined by

$$
c l\left(f_{E}\right)=\widetilde{\cap}\left\{g_{E}: f_{E} \widetilde{\subset} g_{E} \text { and } g_{E} \in \tau^{\prime}\right\} .
$$

Definition $2.14\left({ }^{9}\right)$ Let $(U, \tau, E)$ be a soft topological space over $U . \forall f_{E} \in S(U, E)$, the soft interior of $f_{E}$ is defined by

$$
\operatorname{int}\left(f_{E}\right)=\widetilde{\cup}\left\{g_{E}: g_{E} \widetilde{\subset} f_{E} \text { and } g_{E} \in \tau\right\} .
$$

Proposition $2.15\left({ }^{9}\right)$ Let $(U, \tau, E)$ be a soft topological space over $U$. Then $\forall f_{E} \in S(U, E), \quad \operatorname{int}\left(f_{E}\right)=$ $\widetilde{U}-\operatorname{cl}\left(\widetilde{U}-f_{E}\right)$.

\section{Soft points}

In this section, we will introduce the concept of soft points and investigate the relationship between soft points and soft sets.

\subsection{The concept of soft points}

In this subsection we define soft points, which originate from the concept of fuzzy points (see ${ }^{11,23}$ ).

Definition 3.1 Let $f_{E}^{*} \in S(U, E)$. $f_{E}^{*}$ is called a soft point over $U$, if there exist $e \in E$ and $x \in U$ such that

$$
f^{*}(\varepsilon)= \begin{cases}\{x\}, & \text { if } \varepsilon=e, \\ \emptyset, & \text { if } \varepsilon \in E-\{e\} .\end{cases}
$$

We denote $f_{E}^{*}$ by $\left(x_{e}\right)_{E}$.

In this case, $x$ is called the support point of $\left(x_{e}\right)_{E}$, $\{x\}$ is called the support point set of $\left(x_{e}\right)_{E}$ and $e$ is called the expressive parameter of $\left(x_{e}\right)_{E}$.

Example 3.2 Let $U=\left\{x_{1}, x_{2}, x_{3}, x_{4}, x_{5}\right\}$ and $E=$ $\left\{e_{1}, e_{2}, e_{3}, e_{4}\right\}$. We define $f^{*}\left(e_{1}\right)=\emptyset, f^{*}\left(e_{2}\right)=$ $\emptyset, f^{*}\left(e_{3}\right)=\left\{x_{5}\right\}, f^{*}\left(e_{4}\right)=\emptyset$.

Then $f_{E}^{*}$ is a soft point over $U$. We denote $f_{E}^{*}$ by $\left(\left(x_{5}\right)_{e_{3}}\right)_{E}$, where $x_{5}$ is the support point of $\left(\left(x_{5}\right)_{e_{3}}\right)_{E}$, $\left\{x_{5}\right\}$ is the support point set of $\left(\left(x_{5}\right)_{e_{3}}\right)_{E}$ and $e_{3}$ is the expressive parameter of $\left(\left(x_{5}\right)_{e_{3}}\right)_{E}$.
For $f_{E} \in S(U, E)$, denote

$\left(x_{e}\right)_{E}$ is a soft points over $\left.\mathrm{U}\right\}$.

$$
\mathscr{F}(E)=\left\{\left(x_{e}\right)_{E}: x \in f(e) \text { and } e \in E\right\},
$$$$
P(U, E)=\left\{\left(x_{e}\right)_{E}:\right.
$$

Remark $3.3(1) \quad\left(x_{e}\right)_{E} \in \mathscr{F}(E) \Longleftrightarrow x \in$ $f(e)$ and $e \in E$.

(2) $|\mathscr{F}(E)|=\sum_{e \in E}|f(e)|$.

(3) If $f_{E}=\left(x_{e}\right)_{E}$, then $\mathscr{F}(E)=\left\{\left(x_{e}\right)_{E}\right\}$.

Example 3.4 Let $U=\left\{x_{1}, x_{2}, x_{3}, x_{4}, x_{5}\right\}$ and $E=$ $\left\{e_{1}, e_{2}, e_{3}, e_{4}\right\}$. We define $f\left(e_{1}\right)=\left\{x_{1}, x_{4}\right\}, f\left(e_{2}\right)=$ $U, f\left(e_{3}\right)=\left\{x_{5}\right\}, f\left(e_{4}\right)=\emptyset$. Then

$$
\mathscr{F}(E)=\left\{\left(\left(x_{1}\right)_{e_{1}}\right)_{E},\left(\left(x_{4}\right)_{e_{1}}\right)_{E},\left(\left(x_{1}\right)_{e_{2}}\right)_{E},\left(\left(x_{2}\right)_{e_{2}}\right)_{E},\right.
$$

$\left.\left(\left(x_{3}\right)_{e_{2}}\right)_{E},\left(\left(x_{4}\right)_{e_{2}}\right)_{E},\left(\left(x_{5}\right)_{e_{2}}\right)_{E},\left(\left(x_{5}\right)_{e_{3}}\right)_{E}\right\}$ and

$$
P(U, E)=\left\{\left(\left(x_{i}\right)_{e_{j}}\right)_{E}: 1 \leqslant i \leqslant 5,1 \leqslant j \leqslant 4\right\} .
$$

To illustrate the fact that the soft contain relation, the soft intersection operation, the soft union operation and the soft difference operation on two soft sets can be be translated into the contain relation, the intersection operation, the union operation and the difference operation on two soft point sets (i.e., two ordinary sets), respectively, we give the following Proposition 3.5.

Proposition 3.5 Let $f_{E}, g_{E}, h_{E} \in S(U, E)$.

(1) If $g_{E} \widetilde{\subset} f_{E}$, then $\mathscr{G}(E) \subseteq \mathscr{F}(E)$.

(2) If $f_{E}=g_{E} \widetilde{\cap} h_{E}$, then $\mathscr{F}(E)=\mathscr{G}(E) \cap$ $\mathscr{H}(E)$.

(3) If $f_{E}=g_{E} \widetilde{\cup} h_{E}$, then $\mathscr{F}(E)=\mathscr{G}(E) \cup$ $\mathscr{H}(E)$.

(4) If $f_{E}=g_{E}-h_{E}$, then $\mathscr{F}(E)=\mathscr{G}(E)-$ $\mathscr{H}(E)$.

Proof. (1) This is obvious.

(2) Let $\left(x_{e}\right)_{E} \in \mathscr{F}(E)$. Then $x \in f(e)$. Since $f_{E}=g_{E} \widetilde{\cap} h_{E}$, we have $x \in g(e)$ and $x \in h(e)$. Thus $\left(x_{e}\right)_{E} \in \mathscr{G}(E)$ and $\left(x_{e}\right)_{E} \in \mathscr{F}(E)$. Hence $\left(x_{e}\right)_{E} \in$ $\mathscr{G}(E) \cap \mathscr{H}(E)$. Conversely, the proof is similar.

(3) The proof is similar to (2).

(4) The proof is similar to (2).

Proposition 3.6 (1) If $f_{E}=U_{E}$, then $P(U, E)=$ $\mathscr{F}(E)$.

(2) $P(U, E)=\cup\left\{\mathscr{F}(E): f_{E} \in S(U, E)\right\}$. 
Proof. (1) This is obvious.

(2) Let $f_{E} \in S(U, E)$. Since $f_{E} \widetilde{\subset} U_{E}$, by Proposition 3.5 and (1), $\mathscr{F}(E) \subseteq P(U, E)$. Thus $P(U, E) \supseteq$ $\cup\left\{\mathscr{F}(E): f_{E} \in S(U, E)\right\}$.

Conversely, since $U_{E} \in S(U, E)$, by (1), we have $P(U, E) \subseteq \cup\left\{\mathscr{F}(E): f_{E} \in S(U, E)\right\}$.

Hence $\mathscr{F}(E)=\cup\left\{\mathscr{F}(E): f_{E} \in S(U, E)\right\}$.

\subsection{Soft points and soft sets}

In this subsection, we will investigate the relationship between soft points and soft sets.

Definition 3.7 Let $f_{E} \in S(U, E)$ and $\left(x_{e}\right)_{E} \in$ $P(U, E)$. We define $\left(x_{e}\right)_{E} \widetilde{\in} f_{E}$ by $\left(x_{e}\right)_{E} \widetilde{\subset} f_{E}$.

Note that $\left(x_{e}\right)_{E} \widetilde{\notin} f_{E}$, if $\left(x_{e}\right)_{E} \widetilde{\not} f_{E}$.

Remark $3.8(1)\left(x_{e}\right)_{E}=\left(x^{\prime} e^{\prime}\right)_{E} \Leftrightarrow x=x^{\prime}$ and $e=e^{\prime}$.

(2) $\left(x_{e}\right)_{E} \tilde{\in} f_{E} \Leftrightarrow x \in f(e)$ and $e \in E \Leftrightarrow$ $\left(x_{e}\right)_{E} \in \mathscr{F}(E)$.

(3) $\left(x_{e}\right)_{E} \widetilde{\in} f_{E}$ and $f_{E} \widetilde{\subset} g_{E} \Rightarrow\left(x_{e}\right)_{E} \widetilde{\in} g_{E}$.

(4) $\left(x_{e}\right)_{E} \widetilde{\in}\left(x_{e}\right)_{E}$.

(5) $\left(x_{e}\right)_{E} \widetilde{\in} f_{E} \Leftrightarrow\left(x_{e}\right)_{E} \widetilde{\notin} f_{E}^{\prime}$.

Theorem 3.9 Let $f_{E} \in S(U, E)$. Then $f_{E}=$ $\widetilde{\cup} \mathscr{F}(E)$.

Proof. Denote $h_{E}=\widetilde{U} \mathscr{F}(E)$. Then $h_{E}=$ $\widetilde{U}\left\{\left(x_{e}\right)_{E}: x \in f(e)\right.$ and $\left.e \in E\right\}$. Thus

$$
h_{E}=\widetilde{\bigcup_{e \in E}} \widetilde{\bigcup_{x \in f(e)}}\left(x_{e}\right)_{E}
$$

$$
\begin{aligned}
& \forall \varepsilon \in E, \\
& \quad h(\varepsilon)=\bigcup_{e \in E} \bigcup_{x \in f(e)} x_{e}(\varepsilon)=\left(\bigcup_{x \in f(\varepsilon)} x_{\varepsilon}(\varepsilon)\right) \\
& \cup\left(\bigcup_{e \in E-\{\varepsilon\}} \bigcup_{x \in f(e)} x_{e}(\varepsilon)\right)=\left(\bigcup_{x \in f(\varepsilon)}\{x\}\right) \bigcup \emptyset=f(\varepsilon) .
\end{aligned}
$$

This shows $h_{E}=f_{E}$. Hence $f_{E}=\widetilde{U} \mathscr{F}(E)$.

Remark 3.10 Theorem 3.9 reveals the fact that a soft set can be translated into a soft point set and vice versa.
Theorem 3.11 Let $f_{E}, g_{E} \in S(U, E)$. Then

(1) $f_{E} \widetilde{\subset} g_{E} \Leftrightarrow \mathscr{F}(E) \subseteq \mathscr{G}(E)$.

(2) $f_{E}=g_{E} \Leftrightarrow \mathscr{F}(E)=\mathscr{G}(E)$

Proof. These hold by Proposition 3.5 and Theorem 3.9.

Remark 3.12 Theorem 3.11 illustrates that the soft contain relation and the soft equal relation can be respectively translated into the contain relation and the equal relation on two soft point sets (i.e., two ordinary sets) and vice versa.

When we study some problems of soft sets by using soft points in this paper, we will abide by the following logic thinking: firstly, the soft contain relation, the soft intersection operation, the soft union operation and the soft difference operation on soft sets are translated into the contain relation, the intersection operation, the union operation and the difference operation on soft point sets by Proposition 3.5, respectively; secondly, the relations and operations on ordinary sets (i.e., soft point sets) are realized; thirdly, the results of the relations and operations on ordinary sets are translated into the results on soft sets by Theorem 3.9.

\section{4. $s$-relations on soft sets}

In this section, we introduce the concepts of serial, reflexive, symmetric, transitive and Euclidean $s$-relations on soft sets, and investigate the relationships between these $s$-relations and soft point sets.

Definition 4.1 $\left(^{5}\right)$ Let $A, B \subseteq E, f_{A} \in S(U, A)$ and $g_{B} \in S(U, B) . h_{A \times B}$ is called the cartesian product of $f_{A}$ and $g_{B}$, if $\forall(a, b) \in A \times B, h(a, b)=f(a) \times g(b)$. We write $h_{A \times B}=f_{A} \times g_{B}$.

Definition 4.2 $\left({ }^{5}\right)$ Let $A, B \subseteq E, f_{A} \in S(U, A)$ and $g_{B} \in S(U, B)$.

(1) $R$ is called a relation from $f_{A}$ to $g_{B}$, if $R \widetilde{\subset} f_{A} \times g_{B}$.

(2) $R$ is called a relation on $f_{A}$, if $R \widetilde{\subset} f_{A} \times f_{A}$.

In other words, a relation $R$ from $f_{A}$ to $g_{B}$ is of the form $l_{P}$, where $P \subseteq A \times B$ and $\forall(a, b) \in P$, 
$l(a, b) \subseteq f(a) \times g(b)$.

Definition 4.3 Let $f_{E} \in S(U, E)$. $R$ is called a surjective relation (brief. $s$-relation) on $f_{E}$, if there exists a soft set $l_{E \times E}$ over $U \times U$ such that $R=$ $l_{E \times E} \widetilde{\subset} f_{E} \times f_{E}$.

Remark 4.4 $R$ is a s-relation on $f_{E} \Rightarrow R$ is a relation on $f_{E}$.

Example 4.5 Let $U=\left\{x_{1}, x_{2}, x_{3}, x_{4}, x_{5}\right\}$ and $E=$ $\left\{e_{1}, e_{2}\right\}$. We define $f\left(e_{1}\right)=\left\{x_{1}, x_{3}, x_{5}\right\}, f\left(e_{2}\right)=$ $\left\{x_{2}, x_{4}\right\}$. Then $f_{E} \in S(U, E)$ and $E \times E=$ $\left\{\left(e_{1}, e_{1}\right),\left(e_{1}, e_{2}\right),\left(e_{2}, e_{1}\right),\left(e_{2}, e_{2}\right)\right\}$.

Let $h_{E \times E}=f_{E} \times f_{E}$. Then

$h\left(e_{1}, e_{1}\right)=f\left(e_{1}\right) \times f\left(e_{1}\right), h\left(e_{1}, e_{2}\right)=f\left(e_{1}\right) \times f\left(e_{2}\right)$,

$h\left(e_{2}, e_{1}\right)=f\left(e_{2}\right) \times f\left(e_{1}\right)$ and $h\left(e_{2}, e_{2}\right)=f\left(e_{2}\right) \times f\left(e_{2}\right)$.

(1) Define $l: E \times E \rightarrow 2^{U \times U}$ by

$$
\begin{gathered}
l\left(e_{1}, e_{1}\right)=\left\{\left(x_{1}, x_{1}\right),\left(x_{1}, x_{3}\right),\left(x_{1}, x_{5}\right),\left(x_{3}, x_{3}\right),\right. \\
\left.\left(x_{3}, x_{5}\right),\left(x_{5}, x_{5}\right)\right\}, \\
l\left(e_{1}, e_{2}\right)=f\left(e_{1}\right) \times f\left(e_{2}\right), \\
l\left(e_{2}, e_{1}\right)=\left\{\left(x_{2}, x_{1}\right),\left(x_{2}, x_{3}\right),\left(x_{2}, x_{5}\right),\left(x_{4}, x_{3}\right),\left(x_{4}, x_{5}\right)\right\}
\end{gathered}
$$

and

$$
l\left(e_{2}, e_{2}\right)=f\left(e_{2}\right) \times f\left(e_{2}\right) .
$$

Then

$$
\begin{gathered}
l\left(e_{1}, e_{1}\right) \subseteq h\left(e_{1}, e_{1}\right), \quad l\left(e_{1}, e_{2}\right) \subseteq h\left(e_{1}, e_{2}\right), \\
l\left(e_{2}, e_{1}\right) \subseteq h\left(e_{2}, e_{1}\right) \text { and } l\left(e_{2}, e_{2}\right) \subseteq h\left(e_{2}, e_{2}\right) .
\end{gathered}
$$

So $l_{E \times E} \widetilde{\subset} f_{E} \times f_{E}$

Put $R_{1}=l_{E \times E}$. Then $R_{1}$ is a s-relation on $f_{E}$.

(2) Put $P=\left\{\left(e_{1}, e_{1}\right),\left(e_{1}, e_{2}\right)\right\}$. Then $P \subsetneq E \times E$. Define $k: P \rightarrow 2^{U \times U}$ by

$k\left(e_{1}, e_{1}\right)=f\left(e_{1}\right) \times f\left(e_{1}\right)$ and $k\left(e_{1}, e_{2}\right)=f\left(e_{1}\right) \times f\left(e_{2}\right)$.

Put $R_{2}=k_{P}$. Since $R_{2} \widetilde{\subset} f_{E} \times f_{E}, R_{2}$ is a relation on $f_{E}$. But $R_{2}$ is not a s-relation on $f_{E}$.
Since soft sets can be translated into soft point sets, every relation on a soft set can be translated into a relation on a soft point set. We introduce the following Definition 4.6 for this reason.

Definition 4.6 Let $R$ be a s-relation on $f_{E} \in$ $S(U, E)$. Define a relation $R^{*}$ on $\mathscr{F}(E)$ as follows: for any $\left(x_{e}\right)_{E},\left(x_{e^{\prime}}^{\prime}\right)_{E} \in \mathscr{F}(E)$,

$\left(x_{e}\right)_{E} R^{*}\left(x_{e^{\prime}}^{\prime}\right)_{E} \Leftrightarrow\left(x_{e}\right)_{E} \times\left(x_{e^{\prime}}^{\prime}\right)_{E} \widetilde{\subset} R$.

Then $R^{*}$ is called the relation induced by $R$.

Remark $4.7(1)\left(x_{e}\right)_{E} \times\left(x_{e^{\prime}}^{\prime}\right)_{E} \widetilde{\subset} f_{E} \times f_{E} \Leftrightarrow x \in$ $f(e)$ and $x^{\prime} \in f\left(e^{\prime}\right)$.

(2) Let $R=l_{E \times E} \widetilde{\subset} f_{E} \times f_{E}$. Then

$$
\begin{aligned}
\left(x_{e}\right)_{E} R^{*}\left(x_{e^{\prime}}^{\prime}\right)_{E} & \Leftrightarrow\left(x, x^{\prime}\right) \in l\left(e, e^{\prime}\right) \\
& \Longrightarrow x \in f(e), x^{\prime} \in f\left(e^{\prime}\right) .
\end{aligned}
$$

Definition 4.8 Let $R$ be a s-relation on $f_{E} . \quad R$ is called serial (resp. reflexive, symmetric, transitive, Euclidean), if $R^{*}$ is serial (resp. reflexive, symmetric, transitive, Euclidean).

Let $f_{E} \in \underset{\sim}{S}(U, E)$. Denote $S_{f}(U, E)=\left\{g_{E} \in\right.$ $\left.S(U, E): g_{E} \widetilde{\subset} f_{E}\right\}$.

Let $R$ be a $s$-relation on $f_{E}$ and $R^{*}$ the relation induced by $R . \forall\left(x_{e}\right)_{E} \in \mathscr{F}(E), g_{E} \in S_{f}(X, E)$, put

$$
\begin{gathered}
R^{*}\left(\left(x_{e}\right)_{E}\right)=\left\{\left(x_{e^{\prime}}^{\prime}\right)_{E} \in \mathscr{F}(E):\left(x_{e}\right)_{E} R^{*}\left(x_{e^{\prime}}^{\prime}\right)_{E}\right\}, \\
P_{g}\left(f_{E}, R\right)=\left\{\left(x_{e}\right)_{E} \in \mathscr{F}(E): R^{*}\left(\left(x_{e}\right)_{E}\right) \subseteq \mathscr{G}(E)\right\}, \\
P^{g}\left(f_{E}, R\right)=\left\{\left(x_{e}\right)_{E} \in \mathscr{F}(E): R^{*}\left(\left(x_{e}\right)_{E}\right) \cap \mathscr{G}(E) \neq \emptyset\right\} .
\end{gathered}
$$

Remark 4.9 Let $R$ be a s-relation on $f_{E} \in S(U, E)$ and $R^{*}$ the relation induced by $R$. Then

(1) $R$ is serial $\Leftrightarrow \forall\left(x_{e}\right)_{E} \in \mathscr{F}(E), R^{*}\left(\left(x_{e}\right)_{E}\right) \neq \emptyset$.

(2) $R$ is reflexive $\Leftrightarrow \forall\left(x_{e}\right)_{E} \in \mathscr{F}(E),\left(x_{e}\right)_{E} \in$ $R^{*}\left(\left(x_{e}\right)_{E}\right)$.

(3) $R$ is symmetric $\Leftrightarrow \forall\left(x_{e}\right)_{E},\left(x_{e^{\prime}}^{\prime}\right)_{E} \in \mathscr{F}(E)$, $\left(x_{e^{\prime}}^{\prime}\right)_{E} \in R^{*}\left(\left(x_{e}\right)_{E}\right)$ implies $\left(x_{e}\right)_{E} \in R^{*}\left(\left(x_{e^{\prime}}^{\prime}\right)_{E}\right)$.

(4) $R$ is transitive $\Leftrightarrow \forall\left(x_{e}\right)_{E},\left(x_{e^{\prime}}^{\prime}\right)_{E},\left(x_{e^{\prime \prime}}^{\prime \prime}\right)_{E} \in$ $\mathscr{F}(E),\left(x_{e}\right)_{E} \in R^{*}\left(\left(x_{e^{\prime}}^{\prime}\right)_{E}\right)$ and $\left(x_{e^{\prime}}^{\prime}\right)_{E} \in R^{*}\left(\left(x_{e^{\prime \prime}}^{\prime \prime}\right)_{E}\right)$ implies $\left(x_{e}\right)_{E} \in R^{*}\left(\left(x_{e^{\prime \prime}}^{\prime \prime}\right)_{E}\right)$

$\Leftrightarrow \forall\left(x_{e}\right)_{E},\left(x_{e^{\prime}}^{\prime}\right)_{E} \in \mathscr{F}(E), \quad\left(x_{e^{\prime}}^{\prime}\right)_{E} \in R^{*}\left(\left(x_{e}\right)_{E}\right)$ implies $R^{*}\left(\left(x_{e^{\prime}}^{\prime}\right)_{E}\right) \subseteq R^{*}\left(\left(x_{e}\right)_{E}\right)$. 
(5) $R$ is Euclidean $\Leftrightarrow \forall\left(x_{e}\right)_{E},\left(x_{e^{\prime}}^{\prime}\right)_{E},\left(x_{e^{\prime \prime}}^{\prime \prime}\right)_{E} \in$ $\mathscr{F}(E),\left(x_{e^{\prime}}^{\prime}\right)_{E} \in R^{*}\left(\left(x_{e}\right)_{E}\right)$ and $\left(x_{e^{\prime \prime}}^{\prime \prime}\right)_{E} \in R^{*}\left(\left(x_{e}\right)_{E}\right)$ implies $R^{*}\left(\left(x_{e^{\prime \prime}}^{\prime \prime}\right) \subseteq R^{*}\left(\left(x_{e^{\prime}}^{\prime}\right)_{E}\right)\right.$

$\Leftrightarrow \forall\left(x_{e}\right)_{E},\left(x_{e^{\prime}}^{\prime}\right)_{E} \in \mathscr{F}(E),\left(x_{e^{\prime}}^{\prime}\right)_{E} \in R^{*}\left(\left(x_{e}\right)_{E}\right)$ implies $R^{*}\left(\left(x_{e}\right)_{E}\right) \subseteq R^{*}\left(\left(x_{e^{\prime}}^{\prime}\right)_{E}\right)$.

Lemma 4.10 Let $R$ be a s-relation on $f_{E} \in S(U, E)$. Then $\forall g_{E}, h_{E} \in S_{f}(U, E)$,

(1) $P_{f}\left(f_{E}, R\right)=\mathscr{F}(E)$.

(2) a) $R$ is serial $\Rightarrow P_{g}\left(f_{E}, R\right) \subseteq P^{g}\left(f_{E}, R\right)$.

b) $R$ is reflexive $\Rightarrow P_{g}\left(f_{E}, R\right) \subseteq \mathscr{G}(E) \subseteq$ $P^{g}\left(f_{E}, R\right)$.

(3) a) $g_{E} \widetilde{\subset} h_{E} \Rightarrow P_{g}\left(f_{E}, R\right) \subseteq P_{h}\left(f_{E}, R\right)$;

b) $g_{E} \widetilde{\subset} h_{E} \Rightarrow P^{g}\left(f_{E}, R\right) \subseteq P^{h}\left(f_{E}, R\right)$.

(4) a) $P^{l}\left(f_{E}, R\right)=P^{g}\left(f_{E}, R\right) \cup P^{h}\left(f_{E}, R\right)$ where $l_{E}=g_{E} \widetilde{\cup} h_{E}$; $l_{E}=g_{E} \widetilde{\cap} h_{E}$.

b) $P_{l}\left(f_{E}, R\right)=P_{g}\left(f_{E}, R\right) \cap P_{h}\left(f_{E}, R\right)$ where

Proof. (1) This is obvious.

(2) a) Let $\left(x_{e}\right)_{E} \in P_{g}\left(f_{E}, R\right)$. Thus $R^{*}\left(\left(x_{e}\right)_{E}\right) \subseteq$ $\mathscr{G}(E)$. Since $R$ is serial, by Remark 4.9, $R^{*}\left(\left(x_{e}\right)_{E}\right) \neq$ $\emptyset$. This implies $R^{*}\left(\left(x_{e}\right)_{E}\right) \cap \mathscr{G}(E) \neq \emptyset$. So $\left(x_{e}\right)_{E} \in$ $P^{g}\left(f_{E}, R\right)$. Thus $P_{g}\left(f_{E}, R\right) \subseteq P^{g}\left(f_{E}, R\right)$.

$b)$ Let $\left(x_{e}\right)_{E} \in P_{g}\left(f_{E}, R\right)$. Then $R^{*}\left(\left(x_{e}\right)_{E}\right) \subseteq$ $\mathscr{G}(E)$. Since $R$ is reflexive, by Remark 4.9, we have $\left(x_{e}\right)_{E} \in R^{*}\left(\left(x_{e}\right)_{E}\right) \subseteq \mathscr{G}(E)$. Thus $P_{g}\left(f_{E}, R\right) \subseteq$ $\mathscr{G}(E)$. Since $\left(x_{e}\right)_{E} \in R^{*}\left(\left(x_{e}\right)_{E}\right)$ and $\left(x_{e}\right)_{E} \in \mathscr{G}(E)$, $R^{*}\left(\left(x_{e}\right)_{E}\right) \cap \mathscr{G}(E) \neq \emptyset$. Thus $\mathscr{G}(E) \subseteq P^{g}\left(f_{E}, R\right)$.

(3) a) Let $\left(x_{e}\right)_{E} \in P_{g}\left(f_{E}, R\right)$. Then $R^{*}\left(\left(x_{e}\right)_{E}\right) \subseteq$ $\mathscr{G}(E)$. Since $g_{E} \widetilde{\subset} h_{E}, \mathscr{G}(E) \subseteq \mathscr{H}(E)$ and $R^{*}\left(\left(x_{e}\right)_{E}\right) \subseteq \mathscr{H}(E)$. Thus $\left(x_{e}\right)_{E} \in P_{h}\left(f_{E}, R\right)$. Hence $P_{g}\left(f_{E}, R\right) \subseteq P_{h}\left(f_{E}, R\right)$.

$b$ ) The proof is similar to $a$ ).

(4) a) Let $\left(x_{e}\right)_{E} \in P^{l}\left(f_{E}, R\right)$. Then $R^{*}\left(\left(x_{e}\right)_{E}\right) \cap$ $\mathscr{L}(E) \neq \emptyset$. Since $l_{E}=g_{E} \widetilde{\cup} h_{E}$, by Proposition 3.5, $R^{*}\left(\left(x_{e}\right)_{E}\right) \cap \mathscr{G}(E) \neq \emptyset$ and $R^{*}\left(\left(x_{e}\right)_{E}\right) \cap \mathscr{H}(E) \neq$ $\emptyset$. Thus $\left(x_{e}\right)_{E} \in P^{g}\left(f_{E}, R\right)$ and $\left(x_{e}\right)_{E} \in P^{h}\left(f_{E}, R\right)$. Hence $P^{l}\left(f_{E}, R\right) \subseteq P^{g}\left(f_{E}, R\right) \cup P^{h}\left(f_{E}, R\right)$.

Conversely, this is obvious.

$b$ ) The proof is similar to $a$ ).

\section{Soft rough approximate operations}

In this section, we propose two soft rough approximate operations. Serial, reflexive, symmetric, tran- sitive and Euclidean s-relations are characterized by using them.

Definition 5.1 Let $R$ be a s-relation on $f_{E} \in$ $S(U, E)$. Then the pair $P=\left(f_{E}, R\right)$ is called a soft approximation space. Based on $P$, we define the following operations $\underline{\operatorname{apr}}_{P}, \overline{a p r}_{P}: S_{f}(U, E) \rightarrow S_{f}(U, E)$ by

$$
\underline{\operatorname{apr}}_{P}\left(g_{E}\right)=\widetilde{\cup} P_{g}\left(f_{E}, R\right), \overline{\operatorname{apr}}_{P}\left(g_{E}\right)=\widetilde{\cup} P^{g}\left(f_{E}, R\right),
$$

where $g_{E} \in S_{f}(U, E)$. Then, $\underline{a p r}_{P}$ and $\overline{a p r}_{P}$ are called the soft $P$-lower approximation operator and the soft $P$-upper approximation operator on $f_{E}$, respectively; $\operatorname{apr}_{P}\left(g_{E}\right)$ and $\overline{a p r}_{P}\left(g_{E}\right)$ are called the soft P-lower approximation of $g_{E}$ and the soft $P$ upper approximation of $g_{E}$, respectively.

$g_{E}$ is called a soft P-definable set if $\operatorname{apr}_{P}\left(g_{E}\right)=$ $\overline{\operatorname{apr}}_{P}\left(g_{E}\right) ; g_{E}$ is called a soft $P$-rough set if $\underline{a p r}_{P}\left(g_{E}\right) \neq \overline{a p r}_{P}\left(g_{E}\right)$.

Remark 5.2 In $^{7}$, Feng et al. proposed two operations $\underline{\text { apr }}_{P}, \overline{\text { apr }}_{P}: 2^{U} \rightarrow 2^{U}$ by

$$
\begin{aligned}
& \underline{\operatorname{apr}}_{P}(X)=\{u \in U: \exists e \in E, \text { s.t. } u \in f(e) \subseteq X\}, \\
& \overline{a p r}_{P}(X)=\{u \in U: \exists e \in E, \text { s.t. } u \in f(e) \\
& \text { and } f(e) \cap X \neq \emptyset\} \text {. }
\end{aligned}
$$

where $X \in 2^{U}, P=\left(U, f_{E}\right)$ and $f_{E} \in S(U, E)$.

Lemma 5.3 Let $R$ be a s-relation on $f_{E} \in S(U, E)$. Then $\forall g_{E}, h_{E} \in S_{f}(U, E)$, we have

(1) $h_{E}=\operatorname{apr}_{P}\left(g_{E}\right) \Leftrightarrow \mathscr{H}_{E}=P_{g}\left(f_{E}, R\right)$.

(2) $h_{E}=\overline{\overline{a p r}}_{P}\left(g_{E}\right) \Leftrightarrow \mathscr{H}_{E}=P^{g}\left(f_{E}, R\right)$.

Proof. (1) Sufficiency. This holds by Theorem 3.11 .

Necessity. Denote $P_{g}\left(f_{E}, R\right)=\left\{\left(y_{a}\right)_{E}: y \in\right.$ $X$ and $a \in A\}$ where $X \subseteq U$ and $A \subseteq E$.

Let $\left(x_{e}\right)_{E} \in \mathscr{H}_{E}$. Then $x \in h(e)=\cup\left\{y_{a}(e): y \in\right.$ $X$ and $a \in A$ \}.

We claim that $e \in A$. Otherwise, $y_{a}(e)=\emptyset \forall y \in$ $X$ and $a \in A$. Then $h(e)=\cup\left\{y_{a}(e): y \in X\right.$ and $a \in$ $A\}=\emptyset$, a contradiction. 
Thus $h(e)=\cup\left\{y_{e}(e): y \in X\right\}=\cup\{\{y\}: y \in$ $X\}=X$. This implies $x \in X$. So $\left(x_{e}\right)_{E} \in P_{g}\left(f_{E}, R\right)$.

Conversely, $\left(x_{e}\right)_{E} \in P_{g}\left(f_{E}, R\right)$. Then $x \in X$ and $e \in A$. Note that $h(e)=\cup\left\{y_{a}(e): y \in X\right.$ and $a \in$ $A\}=\cup\left\{y_{e}(e): y \in X\right\}=\cup\{\{y\}: y \in X\}=X$. So $x \in h(e)$. This implies $\left(x_{e}\right)_{E} \in \mathscr{H}_{E}$.

Hence $\mathscr{H}_{E}=P_{g}\left(f_{E}, R\right)$.

(2) The proof is similar to (1).

Lemma 5.4 Let $\left(f_{\alpha}\right)_{E} \in S(U, E)$ for $\alpha \in A \cup B$. Then

$\widetilde{U}\left\{\left(f_{\alpha}\right)_{E}: \alpha \in A \cup B\right\}=\left(\widetilde{\cup}\left\{\left(f_{\alpha}\right)_{E}: \alpha \in\right.\right.$ $A\}) \widetilde{\cup}\left(\widetilde{\cup}\left\{\left(f_{\alpha}\right)_{E}: \alpha \in B\right\}\right)$.

Proof. Denote $C=A \cup B, f_{E}^{C}=\widetilde{\cup}\left\{\left(f_{\alpha}\right)_{E}: \alpha \in C\right\}$, $f_{E}^{A}=\widetilde{\cup}\left\{\left(f_{\alpha}\right)_{E}: \alpha \in A\right\}, f_{E}^{B}=\widetilde{\cup}\left\{\left(f_{\alpha}\right)_{E}: \alpha \in B\right\}$ and $g_{E}=f_{E}^{A} \widetilde{\cup} f_{E}^{B}$.

Then $f^{C}(e)=\cup\left\{f_{\alpha}(e): \alpha \in C\right\} \quad \forall e \in E$ and $g(e)=f^{A}(e) \cup f^{B}(e) \forall e \in E$. Thus $g(e)=$ $\left(\cup\left\{f_{\alpha}(e): \alpha \in A\right\}\right) \cup\left(\cup\left\{f_{\alpha}(e): \alpha \in B\right\}\right)=$ $\cup\left\{f_{\alpha}(e): \alpha \in A \cup B\right\}=\cup\left\{f_{\alpha}(e): \alpha \in C\right\}=f^{C}(e)$.

Lemma 5.5 Let $R$ be a s-relation on $f_{E},\left(x_{e}\right)_{E} \in$ $S_{f}(U, E)$. Denote $h_{E}=\overline{a p r}_{P}\left(\left(x_{e}\right)_{E}\right)$. Then $\mathscr{H}(E)=$ $\left\{\left(y_{\varepsilon}\right)_{E} \in \mathscr{F}(E):\left(x_{e}\right)_{E} \in R^{*}\left(\left(y_{\varepsilon}\right)_{E}\right)\right\}$.

Proof. Denote $g_{E}=\left(x_{e}\right)_{E}$. Then $h_{E}=\overline{a p r}_{P}\left(g_{E}\right)$.

Let $\left(y_{\varepsilon}\right)_{E} \in \mathscr{H}(E)$. By Lemma 5.3, $\left(y_{\varepsilon}\right)_{E} \in$ $P^{g}\left(f_{E}, R\right)$. This implies $R^{*}\left(\left(y_{\varepsilon}\right)_{E}\right) \cap \mathscr{G}(E) \neq \emptyset$. By Remark 3.3, $\mathscr{G}(E)=\left\{\left(x_{e}\right)_{E}\right\}$. So $\left(x_{e}\right)_{E} \in R^{*}\left(\left(y_{\varepsilon}\right)_{E}\right)$. Thus $\left(y_{\varepsilon}\right)_{E} \in\left\{\left(y_{\varepsilon}\right)_{E} \in \mathscr{F}(E):\left(x_{e}\right)_{E} \in R^{*}\left(\left(y_{\varepsilon}\right)_{E}\right)\right\}$.

Conversely, let $\left(y_{\varepsilon}\right)_{E} \in\left\{\left(y_{\varepsilon}\right)_{E} \in \mathscr{F}(E):\left(x_{e}\right)_{E} \in\right.$ $\left.R^{*}\left(\left(y_{\varepsilon}\right)_{E}\right)\right\}$. Then $\left(x_{e}\right)_{E} \in R^{*}\left(\left(y_{\varepsilon}\right)_{E}\right)$. So $\left\{\left(x_{e}\right)_{E}\right\}=$ $R^{*}\left(\left(y_{\varepsilon}\right)_{E}\right) \cap \mathscr{G}(E) \neq \emptyset$. This implies $\left(y_{\varepsilon}\right)_{E} \in$ $P^{g}\left(f_{E}, R\right)$. By Lemma 5.3, $\left(y_{\varepsilon}\right)_{E} \in \mathscr{H}(E)$.

Therefore, $\mathscr{H}(E)=\left\{\left(y_{\varepsilon}\right)_{E} \in \mathscr{F}(E):\left(x_{e}\right)_{E} \in\right.$ $\left.R^{*}\left(\left(y_{\varepsilon}\right)_{E}\right)\right\}$.

Proposition 5.6 Let $R$ be a s-relation on $f_{E} \in$ $S(U, E)$. Then $\forall g_{E}, h_{E} \in S_{f}(U, E)$,

(1) If $g_{E} \widetilde{\subset} h_{E}$, then a) $\underline{a p r}_{P}\left(g_{E}\right) \widetilde{\subset} \underline{a p r}_{P}\left(h_{E}\right)$;

b) $\overline{\overline{a p r}}_{P}\left(g_{E}\right) \widetilde{\subset} \overline{\overline{a p r}}_{P}\left(h_{E}\right)$.

(2) a) $\underset{\operatorname{apr}}{\underline{a p r}_{P}}\left(g_{E} \widetilde{\cap} h_{E}\right)=\underset{\operatorname{apr}}{\operatorname{apr}}\left(g_{E}\right) \widetilde{\cap} \underset{\operatorname{apr}}{{ }_{P}}\left(h_{E}\right)$;

b) $\overline{\overline{a p r}}_{P}\left(g_{E} \widetilde{\cup} h_{E}\right)=\overline{\overline{a p r}}_{P}\left(g_{E}\right) \widetilde{\cup} \overline{\overline{a p r}}_{P}\left(h_{E}\right)$.
Proof. (1) These hold by Lemma 4.10 and Theorem 3.11.

(2) a) Denote $q_{E}=a p r_{P}\left(g_{E}\right), p_{E}=a p r_{P}\left(h_{E}\right)$, $k_{E}=q_{E} \widetilde{\cap} p_{E}, l_{E}=g_{E} \widetilde{\cap} \bar{h}_{E}$ and $w_{E}=a{ }_{p} r_{P}\left(l_{E}\right)$. By Proposition 3.5 and Lemma 4.10, $\mathscr{K}(\overline{E)}=\mathscr{Q}(E) \cap$ $\mathscr{P}(E)$ and $P_{l}\left(f_{E}, R\right)=P_{g}\left(f_{E}, R\right) \cap P_{h}\left(f_{E}, R\right)$.

Let $\left(x_{e}\right)_{E} \in \mathscr{K}(E)$. Then $\left(x_{e}\right)_{E} \in \mathscr{Q}(E)$ and $\left(x_{e}\right)_{E} \in \mathscr{P}(E)$. By Lemma 5.3, $\left(x_{e}\right)_{E} \in P_{g}\left(f_{E}, R\right)$ and $\left(x_{e}\right)_{E} \in P_{h}\left(f_{E}, R\right)$. Thus $\left(x_{e}\right)_{E} \in P_{l}\left(f_{E}, R\right)$. By Lemma 5.3, $\left(x_{e}\right)_{E} \in \mathscr{W}(E)$. By Theorem 3.11,

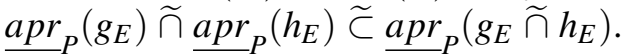

Conversely, $\underline{a p r}_{P}\left(g_{E} \widetilde{\widetilde{\cap} h_{E}}\right) \widetilde{\widetilde{a}} \underline{a p r}_{P}\left(g_{E}\right) \widetilde{\widetilde{\cap}} \underline{a p r}_{P}\left(h_{E}\right)$ is obvious.

b) This holds by Lemma 4.10 and Lemma 5.4.

Proposition 5.7 Let $R$ be a s-relation on $f_{E}$. Then the following are equivalent.

(1) $R$ is serial;

(2) $\forall g_{E} \in S_{f}(U, E), \underline{a p r}_{P}\left(g_{E}\right) \widetilde{\subset} \overline{a p r}_{P}\left(g_{E}\right)$.

Proof. $\quad(1) \Rightarrow(2)$ holds by Lemma 4.10 and Theorem 3.11.

$(2) \Rightarrow(1)$. Let $g_{E} \in S_{f}(U, E)$.

Denote $h_{E}=\underline{a p r}_{P}\left(g_{E}\right)$ and $l_{E}=\overline{a p r}_{P}\left(g_{E}\right)$.

Suppose $\forall\left(x_{e}\right)_{E} \in \mathscr{F}(E), R^{*}\left(\left(x_{e}\right)_{E}\right)=\emptyset$. Then $R^{*}\left(\left(x_{e}\right)_{E}\right) \subseteq \mathscr{G}(E) \forall g_{E} \in S_{f}(U, E)$. This implies $\left(x_{e}\right)_{E} \in P_{g}\left(f_{E}, R\right)$. By Lemma 5.3, $\left(x_{e}\right)_{E} \in \mathscr{H}(E)$. Since $h_{E} \widetilde{\subset} l_{E}, \mathscr{H}(E) \subseteq \mathscr{L}(E)$ and $\left(x_{e}\right)_{E} \in \mathscr{L}(E)$. But $R^{*}\left(\left(x_{e}\right)_{E}\right) \cap \mathscr{G}(E)=\emptyset$. Thus $\left(x_{e}\right)_{E} \notin P^{g}\left(f_{E}, R\right)$. By Lemma 5.3, $\left(x_{e}\right)_{E} \notin \mathscr{L}(E)$, a contradiction. Hence $R^{*}\left(\left(x_{e}\right)_{E}\right) \neq \emptyset$.

Proposition 5.8 Let $R$ be a s-relation on $f_{E}$. Then the following are equivalent.

(1) $R$ is reflexive;

(2) $\forall g_{E} \in S_{f}(U, E)$, $\operatorname{apr}_{P}\left(g_{E}\right) \widetilde{\subset} g_{E} \widetilde{\subset} \overline{a p r}_{P}\left(g_{E}\right)$.

Proof. $\quad(1) \Rightarrow(2)$ holds by Lemma 4.10 and Theorem 3.11.

(2) $\Rightarrow(1)$. Let $g_{E} \in S_{f}(U, E)$. Denote $g_{E}=$ $\left(x_{e}\right)_{E}$ and $h_{E}=\overline{a p r}_{P}\left(g_{E}\right)$.

By (2), $g_{E} \widetilde{\subset} h_{E}$. Then $\mathscr{G}(E) \subseteq \mathscr{H}(E)$. This implies $\left(x_{e}\right)_{E} \in \mathscr{H}(E)$. By Lemma 5.3, $\left(x_{e}\right)_{E} \in P^{g}\left(f_{E}, R\right)$. Thus $R^{*}\left(\left(x_{e}\right)_{E}\right) \cap \mathscr{G}(E) \neq \emptyset$. 
So $R^{*}\left(\left(x_{e}\right)_{E}\right) \cap \mathscr{G}(E)=\left(x_{e}\right)_{E}$. Hence $\left(x_{e}\right)_{E} \in$ $R^{*}\left(\left(x_{e}\right)_{E}\right)$.

Proposition 5.9 Let $R$ be reflexive on $f_{E} \in S(U, E)$. Then

(1) $\operatorname{apr}_{P}\left(f_{E}\right)=\overline{\operatorname{apr}}_{P}\left(f_{E}\right)=f_{E}$.

(2) $\underline{\operatorname{apr}}_{P}(\widetilde{\emptyset})=\overline{\operatorname{apr}}_{P}(\widetilde{\emptyset})=\widetilde{\emptyset}$.

Proof. (1) By Lemma 4.10, $\underline{a p r}_{P}\left(f_{E}\right) \widetilde{\subset} \overline{a p r}_{P}\left(f_{E}\right)$.

Conversely, since $P^{f}\left(\overline{f_{E}, R}\right) \subseteq \mathscr{F}(E)$, then $\overline{\operatorname{apr}}_{P}\left(f_{E}\right) \widetilde{\subset} f_{E}$. By Lemma 4.10, $f_{E}=\underline{a p r}_{P}\left(f_{E}\right)$. Thus $\overline{\operatorname{apr}}_{P}\left(f_{E}\right) \widetilde{\widetilde{a p r}} \underline{a}_{P}\left(f_{E}\right)$. Therefore, $\underline{a p r}_{P}\left(f_{E}\right)=$ $\overline{\operatorname{apr}}_{P}\left(f_{E}\right)=f_{E}$.

(2) This is obvious.

Proposition 5.10 Let $R$ be a s-relation on $f_{E}$. Then the following are equivalent.

(1) $R$ is symmetric;

(2) $\forall g_{E} \in S_{f}(U, E)$,

$\overline{\operatorname{apr}}_{P}\left(\underline{a p r}_{P}\left(g_{E}\right)\right) \widetilde{\subset} g_{E} \widetilde{\subset} \underline{a p r}_{P}\left(\overline{\operatorname{apr}}_{P}\left(g_{E}\right)\right)$.

Proof. $(1) \Rightarrow(2)$. Let $g_{E} \in S_{f}(U, E)$. Denote

$k_{E}=\operatorname{apr}_{P}\left(g_{E}\right), \quad w_{E}=\overline{a p r}_{P}\left(k_{E}\right), \quad h_{E}=$ $\overline{\operatorname{apr}}_{P}\left(g_{E}\right)$ and $l_{E}=\operatorname{apr}_{P}\left(h_{E}\right)$.

Suppose $\mathscr{W}(E)-\mathscr{G}(E) \neq \emptyset$. Pick $\left(x_{e}\right)_{E} \in$ $\mathscr{W}(E)-\mathscr{G}(E)$. Then $\left(x_{e}\right)_{E} \notin \mathscr{G}(E)$ and $\left(x_{e}\right)_{E} \in$ $\mathscr{W}(E)$. By Lemma 5.3, $\left(x_{e}\right)_{E} \in P^{k}\left(f_{E}, R\right)$. This implies $R^{*}\left(\left(x_{e}\right)_{E}\right) \cap \mathscr{K}(E) \neq \emptyset$. Pick $\left(x_{e^{\prime}}^{\prime}\right)_{E} \in$ $R^{*}\left(\left(x_{e}\right)_{E}\right) \cap \mathscr{K}(E)$. Then $\left(x_{e^{\prime}}^{\prime}\right)_{E} \in \mathscr{K}(E)$. By Lemma 5.3, $\left(x_{e}\right)_{E} \in P_{g}\left(f_{E}, R\right)$. This implies $R^{*}\left(\left(x_{e^{\prime}}^{\prime}\right)_{E} \subseteq \mathscr{G}(E)\right.$. Since $R$ is symmetric, $\left(x_{e}\right)_{E} \in$ $R^{*}\left(\left(x_{e^{\prime}}^{\prime}\right)_{E}\right)$. Thus $\left(x_{e}\right)_{E} \in \mathscr{G}(E)$, a contradiction. Hence $\mathscr{W}(E) \subseteq \mathscr{G}(E)$. By Theorem 3.11, $w_{E} \widetilde{\subset} g_{E}$.

Therefore, $\overline{\operatorname{apr}}_{P}\left(\operatorname{apr}_{P}\left(g_{E}\right)\right) \widetilde{\subset} g_{E}$.

Suppose $\mathscr{G}(E)-\mathscr{L}(E) \neq \emptyset$. Pick $\left(x_{e}\right)_{E} \in$ $\mathscr{G}(E)-\mathscr{L}(E)$. Then $\left(x_{e}\right)_{E} \in \mathscr{G}(E)$ and $\left(x_{e}\right)_{E} \notin$ $\mathscr{L}(E)$. By Lemma 5.3, $\left(x_{e}\right)_{E} \notin P_{h}\left(f_{E}, R\right)$. This implies $R^{*}\left(\left(x_{e}\right)_{E}\right) \nsubseteq \mathscr{H}(E)$. Thus $R^{*}\left(\left(x_{e}\right)_{E}\right)-$ $\mathscr{H}(E) \neq \emptyset$. Pick $\left(x_{e^{\prime}}^{\prime}\right)_{E} \in R^{*}\left(\left(x_{e}\right)_{E}\right)-\mathscr{H}(E)$. Then $\left(x_{e^{\prime}}^{\prime}\right)_{E} \notin \mathscr{H}(E)$. By Lemma 5.3, $\left(x_{e^{\prime}}^{\prime}\right)_{E} \notin P^{g}\left(f_{E}, R\right)$. This implies $R^{*}\left(\left(x_{e^{\prime}}^{\prime}\right)_{E}\right) \cap \mathscr{G}(E)=\emptyset$. Since $\left(x_{e^{\prime}}^{\prime}\right)_{E} \in$ $R^{*}\left(\left(x_{e}\right)_{E}\right)$, by $R$ is symmetric, we have $\left(x_{e}\right)_{E} \in$ $R^{*}\left(\left(x_{e^{\prime}}^{\prime}\right)_{E}\right)$. Thus $\mathscr{G}(E)=\emptyset$, a contradiction. Hence $\mathscr{G}(E) \subseteq \mathscr{L}(E)$. By Theorem 3.11, $g_{E} \widetilde{\subset} l_{E}$.

Therefore, $g_{E} \widetilde{\subset} \underset{\operatorname{apr}_{P}}{ }\left(\overline{\operatorname{apr}}_{P}\left(g_{E}\right)\right)$.
$(2) \Rightarrow(1)$. Let $\left(x_{e}\right)_{E},\left(x_{e^{\prime}}^{\prime}\right)_{E} \in \mathscr{F}(E)$ with $\left(x_{e^{\prime}}^{\prime}\right)_{E} \in R^{*}\left(\left(x_{e}\right)_{E}\right)$. Denote

$$
g_{E}=\left(x_{e}\right)_{E}, h_{E}=\overline{a p r}_{P}\left(g_{E}\right) \text { and } l_{E}=\underline{a p r}_{P}\left(h_{E}\right) \text {. }
$$

By Lemma 5.3 and Lemma 5.5, $\mathscr{L}_{E}=P_{h}\left(f_{E}, R\right)$ and

$\mathscr{H}(E)=\left\{\left(y_{\varepsilon}\right)_{E} \in \mathscr{F}(E):\left(x_{e}\right)_{E} \in R^{*}\left(\left(y_{\varepsilon}\right)_{E}\right)\right\}$.

Then $g_{E} \widetilde{\subset} l_{E} \widetilde{\subset} h_{E}$. This implies $\left(x_{e}\right)_{E} \in \mathscr{L}(E) \subseteq$ $\mathscr{H}(E)$. So $\left(x_{e}\right)_{E} \in P^{g}\left(f_{E}, R\right)$. Thus $R^{*}\left(\left(x_{e}\right)_{E}\right) \subseteq$ $\mathscr{G}(E)$. Since $\left(x_{e^{\prime}}^{\prime}\right)_{E} \in R^{*}\left(\left(x_{e}\right)_{E}\right),\left(x_{e^{\prime}}^{\prime}\right)_{E} \in \mathscr{G}(E)$. Then $\left(x_{e^{\prime}}^{\prime}\right)_{E}=\left(x_{e}\right)_{E}$. Hence $\left(x_{e^{\prime}}^{\prime}\right)_{E} \in \mathscr{H}(E)$. By Lemma 5.5, $\left(x_{e}\right)_{E} \in R^{*}\left(\left(x_{e^{\prime}}^{\prime}\right)_{E}\right)$.

Therefore, $R$ is symmetric.

Lemma 5.11 Let $R$ be reflexive on $f_{E} \in S(U, E)$ and let $g_{E}, h_{E} \in S_{f}(U, E)$.

(1) If $h_{E}=\operatorname{apr}_{P}\left(g_{E}\right)$ and $R$ is transitive, then $P_{g}\left(f_{E}, R\right)=P_{h}\left(f_{E}, R\right) \subseteq P^{h}\left(f_{E}, R\right) \subseteq P^{g}\left(f_{E}, R\right)$;

(2) If $h_{E}=\overline{a p r}_{P}\left(g_{E}\right)$ and $R$ is Euclidean, then $P_{g}\left(f_{E}, R\right) \subseteq P^{g}\left(f_{E}, R\right) \subseteq P_{h}\left(f_{E}, R\right) \subseteq P^{h}\left(f_{E}, R\right)$.

Proof. (1) Let $h_{E}=\operatorname{apr}_{P}\left(g_{E}\right)$. Since $\operatorname{apr}_{P}\left(g_{E}\right) \widetilde{\subset} g_{E}, h_{E} \widetilde{\subset} g_{E}$. By Lemma 4.10, $P_{g}\left(f_{E}, R\right) \supseteq P_{h}\left(f_{E}, R\right) \subseteq P^{h}\left(f_{E}, R\right) \subseteq P^{g}\left(f_{E}, R\right)$. It suffices to show that $P_{g}\left(f_{E}, R\right) \subseteq P_{h}\left(f_{E}, R\right)$.

Suppose $P_{g}\left(f_{E}, R\right)-P_{h}\left(f_{E}, R\right) \neq \emptyset$. Pick $\left(x_{e}\right)_{E} \in$ $P_{g}\left(f_{E}, R\right)-P_{h}\left(f_{E}, R\right)$. Then $R^{*}\left(\left(x_{e}\right)_{E}\right) \subseteq \mathscr{G}(E)$ and $R^{*}\left(\left(x_{e}\right)_{E}\right) \not \subset \mathscr{H}(E)$, and so $R^{*}\left(\left(x_{e}\right)_{E}\right)-\mathscr{H}(E) \neq$ $\emptyset$. Pick $\left(x_{\rho^{\prime}}^{\prime}\right)_{E} \in R^{*}\left(\left(x_{e}\right)_{E}\right)-\mathscr{H}(E)$. Since $R$ is transitive, $R^{*}\left(\left(x_{e^{\prime}}^{\prime}\right)_{E}\right) \subseteq R^{*}\left(\left(x_{e}\right)_{E}\right) \subseteq \mathscr{G}(E)$. Thus $\left(x_{e^{\prime}}^{\prime}\right)_{E} \in P_{g}\left(f_{E}, R\right)$. By Lemma 5.3, $\left(x_{e^{\prime}}^{\prime}\right)_{E} \in \mathscr{H}(E)$. But $\left(x_{e^{\prime}}^{\prime}\right)_{E} \notin \mathscr{H}(E)$, a contradiction. Therefore, $P_{g}\left(f_{E}, R\right) \subseteq P_{h}\left(f_{E}, R\right)$

(2) Let $h_{E}=\overline{a p r}_{P}\left(g_{E}\right)$. Since $g_{E} \widetilde{\subset} \overline{a p r}_{P}\left(g_{E}\right)$, $g_{E} \widetilde{\subset} h_{E}$. By Lemma 4.10, $P_{g}\left(f_{E}, R\right) \subseteq P^{g}\left(f_{E}, R\right)$ and $P_{h}\left(f_{E}, R\right) \subseteq P^{h}\left(f_{E}, R\right)$. It suffices to show that $P^{g}\left(f_{E}, R\right) \subseteq P_{h}\left(f_{E}, R\right)$.

Suppose $P^{g}\left(f_{E}, R\right)-P_{h}\left(f_{E}, R\right) \neq \emptyset$. Pick $\left(x_{e}\right)_{E} \in$ $P^{g}\left(f_{E}, R\right)-P_{h}\left(f_{E}, R\right)$. Then $R^{*}\left(\left(x_{e}\right)_{E}\right) \cap \mathscr{G}(E) \neq \emptyset$ and $R^{*}\left(\left(x_{e}\right)_{E}\right) \not \mathscr{H}(E)$. Pick $\left(x_{e^{\prime \prime}}^{\prime \prime}\right)_{E} \in R^{*}\left(\left(x_{e}\right)_{E}\right) \cap$ $\mathscr{G}(E)$ and $\left(x_{e^{\prime}}^{\prime}\right)_{E} \in R^{*}\left(\left(x_{e}\right)_{E}\right)-\mathscr{H}(E)$. Then $\left(x_{e^{\prime}}^{\prime}\right)_{E} \notin \mathscr{H}(E)$. Since $R$ is Euclidean, $\left(x_{e^{\prime \prime}}^{\prime \prime}\right)_{E} \in$ $R^{*}\left(\left(x_{e^{\prime}}^{\prime}\right)_{E}\right)$. That implies $R^{*}\left(\left(x_{e^{\prime}}^{\prime}\right)_{E}\right) \cap \mathscr{G}(E) \neq \emptyset$. Thus $\left(x_{e^{\prime}}^{\prime}\right)_{E} \in P^{g}\left(f_{E}, R\right)$. By Lemma 5.3, $\left(x_{e^{\prime}}^{\prime}\right)_{E} \in$ $\mathscr{H}(E)$, a contradiction. Therefore, $P^{g}\left(f_{E}, R\right) \subseteq$ $P_{h}\left(f_{E}, R\right)$. 
Proposition 5.12 Let $R$ be reflexive on $f_{E} \in$ $S(U, E)$. Then the following are equivalent.

(1) $R$ is transitive;

(2) $\forall g_{E} \in S_{f}(U, E)$,

$\underset{\operatorname{apr}}{P}\left(g_{E}\right) \widetilde{\subset} \underline{a p r}_{P}\left(\underline{a p r}_{P}\left(g_{E}\right)\right) \widetilde{\subset} \overline{\operatorname{apr}}_{P}\left(\overline{a p r}_{P}\left(g_{E}\right)\right)$ $\widetilde{\subset} \overline{\overline{a p r}}_{P}\left(g_{E}\right)$.

Proof. $\quad(1) \Rightarrow(2)$. Let $g_{E} \in S_{f}(U, E)$. Denote

$$
h_{E}=\underline{a p r}_{P}\left(g_{E}\right), k_{E}=\overline{a p r}_{P}\left(g_{E}\right) \text { and } l_{E}=\overline{\operatorname{apr}}_{P}\left(k_{E}\right) \text {. }
$$

We will prove $h_{E} \widetilde{\subset} \underset{\operatorname{apr}_{P}}{ }\left(h_{E}\right)$. We can suppose $P_{g}\left(f_{E}, R\right) \neq \emptyset . \forall\left(x_{e}\right)_{E} \in \overline{P_{g}}\left(f_{E}, R\right)$, by Lemma 5.11, $P_{g}\left(f_{E}, R\right)=P_{h}\left(f_{E}, R\right)$, then $\left(x_{e}\right)_{E} \in P_{h}\left(f_{E}, R\right)$. Hence $\underline{\operatorname{apr}}_{P}\left(g_{E}\right) \widetilde{\subset} \underline{\operatorname{apr}}_{P}\left(\underline{\operatorname{apr}}_{P}\left(g_{E}\right)\right)$. By Proposition 5.7,

$\operatorname{apr}_{P}\left(\operatorname{apr}_{P}\left(g_{E}\right)\right) \widetilde{\widetilde{C}} \overline{\operatorname{apr}}_{P}\left(\overline{\operatorname{apr}}_{P}\left(g_{E}\right)\right)$.

Suppose that $\mathscr{L}(E)-\mathscr{K}(E) \neq \emptyset$. Pick $\left(x_{e}\right)_{E} \in$ $\mathscr{L}(E)-\mathscr{K}(E)$. Then $\left(x_{e}\right)_{E} \in \mathscr{L}(E)$. By Lemma 5.3, $\left(x_{e}\right)_{E} \in P^{k}\left(f_{E}, R\right)$. This implies $R^{*}\left(\left(x_{e}\right)_{E}\right) \cap$ $\mathscr{K}(E) \neq \emptyset$. Pick $\left(x_{e^{\prime}}^{\prime}\right)_{E} \in R^{*}\left(\left(x_{e}\right)_{E}\right) \cap \mathscr{K}(E)$. Then $\left(x_{e^{\prime}}^{\prime}\right)_{E} \in \mathscr{K}(E)$. By Lemma 5.3, $\left(x_{e}\right)_{E} \in P^{g}\left(f_{E}, R\right)$. This implies $R^{*}\left(\left(x_{e^{\prime}}^{\prime}\right)_{E} \cap \mathscr{G}(E) \neq \emptyset\right.$. Thus $\mathscr{G}(E) \neq$ $\emptyset$. Since $\left(x_{e}\right)_{E} \notin \mathscr{K}(E)$, by Lemma 5.3, we have $\left(x_{e}\right)_{E} \notin P^{g}\left(f_{E}, R\right)$. So $R^{*}\left(\left(x_{e}\right)_{E}\right) \cap \mathscr{G}(E)=\emptyset$. since $R$ is reflexive, $\left(x_{e}\right)_{E} \in R^{*}\left(\left(x_{e}\right)_{E}\right)$. Thus $\mathscr{G}(E)=\emptyset$, a contradiction. Hence $\mathscr{L}(E) \subseteq \mathscr{K}(E)$. By Theorem $3.11, l_{E} \widetilde{\subset} k_{E}$.

Therefore, $\overline{\operatorname{apr}}_{P}\left(\overline{\operatorname{apr}}_{P}\left(g_{E}\right)\right) \widetilde{\subset} \overline{a p r}_{P}\left(g_{E}\right)$.

$(2) \Rightarrow(1)$. Let $\left(x_{e}\right)_{E},\left(x_{e^{\prime}}^{\prime}\right)_{E},\left(x_{e^{\prime \prime}}^{\prime \prime}\right)_{E} \in \mathscr{F}(E)$ with $\left(x_{e}\right)_{E} \in R^{*}\left(\left(x_{e^{\prime}}^{\prime}\right)_{E}\right)$ and $\left(x_{e^{\prime}}^{\prime}\right)_{E} \in R^{*}\left(\left(x_{e^{\prime \prime}}^{\prime \prime}\right)_{E}\right)$. Denote

$$
g_{E}=\left(x_{e}\right)_{E}, h_{E}=\overline{a p r}_{P}\left(g_{E}\right) \text { and } l_{E}=\overline{a p r}_{P}\left(h_{E}\right) .
$$

By Lemma 5.3 and Lemma 5.5, $\mathscr{L}_{E}=P^{h}\left(f_{E}, R\right)$ and

$$
\mathscr{H}(E)=\left\{\left(y_{\varepsilon}\right)_{E} \in \mathscr{F}(E):\left(x_{e}\right)_{E} \in R^{*}\left(\left(y_{\varepsilon}\right)_{E}\right)\right\} .
$$

$\left(x_{e}\right)_{E} \in R^{*}\left(\left(x_{e^{\prime}}^{\prime}\right)_{E}\right)$ implies $\left(x_{e}\right)_{E} \in \mathscr{H}(E)$. Note that $\left(x_{e^{\prime}}^{\prime}\right)_{E} \in R^{*}\left(\left(x_{e^{\prime \prime}}^{\prime \prime \prime}\right)_{E}\right)$. Then $R^{*}\left(\left(x_{e^{\prime \prime}}^{\prime \prime}\right)_{E}\right) \cap \mathscr{H}(E) \neq \emptyset$. So $\left(x_{e^{\prime \prime}}^{\prime \prime}\right)_{E} \in P^{h}\left(f_{E}, R\right)=\mathscr{L}(E)$.

Since $\overline{a p r}_{P}\left(\overline{a p r}_{P}\left(\left(x_{e}\right)_{E}\right)\right) \quad \widetilde{C} \quad \overline{a p r}_{P}\left(\left(x_{e}\right)_{E}\right)$, $\mathscr{L}(E) \subseteq \mathscr{H}(E)$. Thus $\left(x_{e^{\prime \prime}}^{\prime \prime}\right)_{E} \in \mathscr{H}(E)$. By Lemma 5.5, $\left(x_{e}\right)_{E} \in R^{*}\left(\left(x_{e^{\prime \prime}}^{\prime \prime}\right)_{E}\right)$.

Therefore, $R$ is transitive.

Proposition 5.13 Let $R$ be reflexive on $f_{E} \in$ $S(U, E)$. Then the following are equivalent.
(1) $R$ is Euclidean;
(2) $\forall g_{E} \in S_{f}(U, E)$,
$\overline{\operatorname{apr}}_{P}\left(\underline{a p r}_{P}\left(g_{E}\right)\right) \widetilde{\subset} \underline{a p r}_{P}\left(g_{E}\right) \widetilde{\subset} \overline{a p r}_{P}\left(g_{E}\right)$
$\widetilde{\sim} \underline{a p r}_{P}\left(\overline{\operatorname{apr}}_{P}\left(g_{E}\right)\right)$.

Proof. $\quad(1) \Rightarrow(2)$. Let $g_{E} \in S_{f}(U, E)$. Denote

$k_{E}=\underline{a p r}_{P}\left(g_{E}\right), l_{E}=\overline{a p r}_{P}\left(k_{E}\right)$ and $h_{E}=\overline{\operatorname{apr}}_{P}\left(g_{E}\right)$.

Suppose $\mathscr{L}(E)-\mathscr{K}(E) \neq \emptyset$. Pick $\left(x_{e}\right)_{E} \in$ $\mathscr{L}(E)-\mathscr{K}(E)$. Then $\left(x_{e}\right)_{E} \notin \mathscr{K}(E)$ and $\left(x_{e}\right)_{E} \in$ $\mathscr{L}(E)$. By Lemma 5.3, $\quad\left(x_{e}\right)_{E} \in P^{k}\left(f_{E}, R\right)$. This implies $R^{*}\left(\left(x_{e}\right)_{E}\right) \cap \mathscr{K}(E) \neq \emptyset$. Pick $\left(x_{e^{\prime}}^{\prime}\right)_{E} \in R^{*}\left(\left(x_{e}\right)_{E}\right) \cap \mathscr{K}(E)$. Then $\left(x_{e^{\prime}}^{\prime}\right)_{E} \in \mathscr{K}(E)$. By Lemma 5.3, $\left(x_{e}\right)_{E} \in P_{g}\left(f_{E}, R\right)$. This implies $R^{*}\left(\left(x_{e^{\prime}}^{\prime}\right)_{E} \subseteq \mathscr{G}(E)\right.$. Since $R$ is Euclidean, $R^{*}\left(\left(x_{e}\right)_{E}\right) \subseteq R^{*}\left(\left(x_{e^{\prime}}^{\prime}\right)_{E}\right)$. Thus $R^{*}\left(\left(x_{e}\right)_{E}\right) \subseteq \mathscr{G}(E)$. Since $\left(x_{e}\right)_{E} \notin \mathscr{K}(E)$, by Lemma 5.3, $\left(x_{e}\right)_{E} \notin$ $P_{g}\left(f_{E}, R\right)$. So $R^{*}\left(\left(x_{e}\right)_{E}\right) \nsubseteq \mathscr{G}(E)$, a contradiction. Hence $\mathscr{L}(E) \subseteq \mathscr{K}(E)$. By Theorem 3.11, $l_{E} \widetilde{\subset} k_{E}$.

Therefore, $\overline{\operatorname{apr}}_{P}\left(\underline{a p r}_{P}\left(g_{E}\right)\right) \widetilde{\widetilde{C a p r}}\left(\underline{\underline{a}}_{P}\left(g_{E}\right)\right.$.

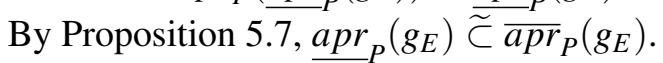

We will prove $h_{E} \underset{\widetilde{C}}{a p r_{P}}\left(h_{E}\right)$. Suppose $P^{g}\left(f_{E}, R\right) \neq \emptyset . \quad \forall\left(x_{e}\right)_{E} \in \bar{P}^{g}\left(f_{E}, R\right)$, by Lemma 5.11, $P^{g}\left(f_{E}, R\right) \subseteq P_{h}\left(f_{E}, R\right)$. Then $\left(x_{e}\right)_{E} \in P_{h}\left(f_{E}, R\right)$. Hence $\overline{\operatorname{apr}}_{P}\left(g_{E}\right) \widetilde{\subset} \operatorname{apr}_{P}\left(\overline{\operatorname{apr}}_{P}\left(g_{E}\right)\right)$.

$(2) \Rightarrow(1)$ Let $\left({\left.\overline{x_{e}}\right)_{E}}_{,},\left(x_{e^{\prime}}^{\prime}\right)_{E},\left(x_{e^{\prime \prime}}^{\prime \prime}\right)_{E} \in \mathscr{F}(E)\right.$ with $\left(x_{e}\right)_{E} \in R^{*}\left(\left(x_{e^{\prime \prime}}^{\prime \prime}\right)_{E}\right)$ and $\left(x_{e^{\prime}}^{\prime}\right)_{E} \in R^{*}\left(\left(x_{e^{\prime \prime}}^{\prime \prime}\right)_{E}\right)$. Denote

$$
g_{E}=\left(x_{e}\right)_{E}, h_{E}=\overline{a p r}_{P}\left(g_{E}\right) \text { and } l_{E}=\underline{a p r}_{P}\left(h_{E}\right) \text {. }
$$

By Lemma 5.3 and Lemma 5.5, $\mathscr{L}_{E}=P_{h}\left(f_{E}, R\right)$ and

$$
\mathscr{H}(E)=\left\{\left(y_{\varepsilon}\right)_{E} \in \mathscr{F}(E):\left(x_{e}\right)_{E} \in R^{*}\left(\left(y_{\varepsilon}\right)_{E}\right)\right\} .
$$

$\left(x_{e}\right)_{E} \in R^{*}\left(\left(x_{e^{\prime \prime}}^{\prime \prime}\right)_{E}\right)$ implies $\left(x_{e^{\prime \prime}}^{\prime \prime}\right)_{E} \in \mathscr{H}(E)$. Since $\left.\overline{a p r}_{P}\left(g_{E}\right) \widetilde{\subset} \underline{a p r}_{P}\left(\overline{a p r}_{P}\left(g_{E}\right)\right)\right), \mathscr{H}(E) \subseteq \mathscr{L}(E)$. So $\left(x_{e^{\prime \prime}}^{\prime \prime}\right)_{E} \in \mathscr{L} \overline{(E)}=P_{h}\left(f_{E}, R\right)$. Thus $R^{*}\left(\left(x_{e^{\prime \prime}}^{\prime \prime}\right)_{E}\right) \subseteq$ $\mathscr{H}(E)$. Note that $\left(x_{e^{\prime}}^{\prime}\right)_{E} \in R^{*}\left(\left(x_{e^{\prime \prime}}^{\prime \prime}\right)_{E}\right)$. Then $\left(x_{e^{\prime}}^{\prime}\right)_{E} \in$ $\mathscr{H}(E)$. By Lemma 5.5, $\left(x_{e}\right)_{E} \in R^{*}\left(\left(x_{e^{\prime}}^{\prime}\right)_{E}\right)$.

Therefore, $R$ is Euclidean.

\section{Soft topologies induced by $s$-relations on special soft sets}

In this section, we investigate soft topologies induced by a reflexive $s$-relation on a special soft set and give their structure. 


\section{1. $s$-relations on $\widetilde{U}$}

Proposition 6.1 Let $R$ be a s-relation on $\widetilde{U}$. Then $\forall g_{E} \in S(U, E)$, we have
(1) $\operatorname{apr}_{P}\left(g_{E}\right)=\widetilde{U}-\overline{a p r}_{P}\left(\widetilde{U}-g_{E}\right)$;
(2) $\overline{\overline{a p r}}_{P}\left(g_{E}\right)=\widetilde{U}-\underline{a p r}_{P}\left(\widetilde{U}-g_{E}\right)$.

Proof. (1) Denote $h_{E}=\widetilde{U}-g_{E}, q_{E}=\overline{a p r}_{P}\left(h_{E}\right)$, $l_{E}=\widetilde{U}-q_{E}$ and $k_{E}=\operatorname{apr}_{P}\left(g_{E}\right)$.

To prove $l_{E} \widetilde{\subset} k_{E}$, by Theorem 3.11 , it suffices to show $\mathscr{L}(E) \subseteq \mathscr{K}(E)$.

Suppose $\mathscr{L}(E)-\mathscr{K}(E) \neq \emptyset$. Pick $\left(x_{e}\right)_{E} \in$ $\mathscr{L}(E)-\mathscr{K}(E)$. Then $\left(x_{e}\right)_{E} \notin \mathscr{K}(E)$. By Lemma 5.3, $\left(x_{e}\right)_{E} \notin P_{g}\left(f_{E}, R\right)$. Thus $R^{*}\left(\left(x_{e}\right)_{E}\right) \nsubseteq \mathscr{G}(E)$. Pick $\left(x_{e^{\prime}}^{\prime}\right)_{E} \in R^{*}\left(\left(x_{e}\right)_{E}\right)-\mathscr{G}(E)$. Then $\left(x_{e^{\prime}}^{\prime}\right)_{E} \notin$ $\mathscr{G}(E)$. This implies $x^{\prime} \notin g\left(e^{\prime}\right)$. So $x^{\prime} \in U-g\left(e^{\prime}\right)=$ $h\left(e^{\prime}\right)$.

Since $\left(x_{e}\right)_{E} \in \mathscr{L}(E),\left(x_{e}\right)_{E} \in \mathscr{U}(E)-\mathscr{Q}(E)$. Then $\left(x_{e}\right)_{E} \notin \mathscr{Q}(E)$. By Lemma 5.3, $\left(x_{e}\right)_{E} \notin$ $P^{h}\left(f_{E}, R\right)$. So $R^{*}\left(\left(x_{e}\right)_{E}\right) \cap \mathscr{H}(E)=\emptyset$. Since $\left(x_{e^{\prime}}^{\prime}\right)_{E} \in R^{*}\left(\left(x_{e}\right)_{E}\right),\left(x_{e^{\prime}}^{\prime}\right)_{E} \notin \mathscr{H}(E)$. This implies $x^{\prime} \notin h\left(e^{\prime}\right)$, a contradiction. Hence $\mathscr{L}(E) \subseteq \mathscr{K}(E)$.

Therefore, $\widetilde{U}-\overline{a p r}_{P}\left(\widetilde{U}-g_{E}\right) \widetilde{\subset} \underline{a p r}_{P}\left(g_{E}\right)$.

Conversely, to prove $k_{E} \widetilde{\subset} l_{E}=\widetilde{U}-q_{E}$, by Remark 2.11, it suffices to show $k_{E} \widetilde{\cap} q_{E}=\widetilde{\emptyset}$.

Suppose $w_{E}=k_{E} \widetilde{\cap} q_{E} \neq \widetilde{\emptyset}$. By Proposition 3.5, $\mathscr{W}(E)=\mathscr{K}(E) \cap \mathscr{Q}(E)$. Pick $\left(x_{e}\right)_{E} \in$ $\mathscr{W}(E)$. Then $\left(x_{e}\right)_{E} \in \mathscr{K}(E)$ and $\left(x_{e}\right)_{E} \in \mathscr{Q}(E)$. By Lemma 5.3, $\left(x_{e}\right)_{E} \in P_{g}\left(f_{E}, R\right)$ and $\left(x_{e}\right)_{E} \in P^{h}\left(f_{E}, R\right)$. Thus $R^{*}\left(\left(x_{e}\right)_{E}\right) \subseteq \mathscr{G}(E)$ and $R^{*}\left(\left(x_{e}\right)_{E}\right) \cap \mathscr{H}(E) \neq \emptyset$. Pick $\left(x_{e^{\prime}}^{\prime}\right)_{E} \in R^{*}\left(\left(x_{e}\right)_{E}\right) \cap \mathscr{H}(E)$. Then $\left(x_{e^{\prime}}^{\prime}\right)_{E} \in$ $\mathscr{H}(E)$. Thus $x^{\prime} \in h\left(e^{\prime}\right)=U-g\left(e^{\prime}\right)$ and so $x^{\prime} \notin$ $g\left(e^{\prime}\right)$. But $\left(x_{e^{\prime}}^{\prime}\right)_{E} \in R^{*}\left(\left(x_{e}\right)_{E}\right)$. This implies $\left(x_{e^{\prime}}^{\prime}\right)_{E} \in$ $\mathscr{G}(E)$. Thus $x^{\prime} \in g\left(e^{\prime}\right)$, a contradiction. Hence $\operatorname{apr}_{P}\left(g_{E}\right) \widetilde{\subset} \widetilde{U}-\overline{a p r}_{P}\left(\widetilde{U}-g_{E}\right)$.

Therefore, $\operatorname{apr}_{P}\left(g_{E}\right)=\widetilde{U}-\overline{a p r}_{P}\left(\widetilde{U}-g_{E}\right)$.

(2) Denote $\bar{h}_{E}=\widetilde{U}-g_{E}, q_{E}=\underline{a p r}_{P}\left(h_{E}\right), l_{E}=$ $\widetilde{U}-q_{E}$ and $k_{E}=\overline{a p r}_{P}\left(g_{E}\right)$.

To prove $l_{E} \widetilde{\subset} k_{E}$, by Theorem 3.11, it suffices to show $\mathscr{L}(E) \subseteq \mathscr{K}(E)$.

Suppose $\mathscr{L}(E)-\mathscr{K}(E) \neq \emptyset$. Pick $\left(x_{e}\right)_{E} \in$ $\mathscr{L}(E)-\mathscr{K}(E)$. Then $\left(x_{e}\right)_{E} \notin \mathscr{K}(E)$. By Lemma 5.3, $\left(x_{e}\right)_{E} \notin P^{g}\left(f_{E}, R\right)$. Then $R^{*}\left(\left(x_{e}\right)_{E}\right) \cap \mathscr{G}(E)=\emptyset$.

Since $\left(x_{e}\right)_{E} \in \mathscr{L}(E),\left(x_{e}\right)_{E} \in \mathscr{U}(E)-\mathscr{Q}(E)$. Then $\left(x_{e}\right)_{E} \notin \mathscr{Q}(E)$. By Lemma 5.3, $\left(x_{e}\right)_{E} \notin$
$P_{h}\left(f_{E}, R\right)$. Then $R^{*}\left(\left(x_{e}\right)_{E}\right) \nsubseteq \mathscr{H}(E)$ and so $R^{*}\left(\left(x_{e}\right)_{E}\right)-\mathscr{H}(E) \neq \emptyset$. Pick $\left(x_{e^{\prime}}^{\prime}\right)_{E} \in R^{*}\left(\left(x_{e}\right)_{E}\right)-$ $\mathscr{H}(E)$. Then $\left(x_{e^{\prime}}^{\prime}\right)_{E} \notin \mathscr{H}(E)$. Thus $x^{\prime} \notin h\left(e^{\prime}\right)=$ $g^{\prime}\left(e^{\prime}\right)=U-g\left(e^{\prime}\right)$ and so $x^{\prime} \in g\left(e^{\prime}\right)$.

Since $\left(x_{e^{\prime}}^{\prime}\right)_{E} \in R^{*}\left(\left(x_{e}\right)_{E}\right),\left(x_{e^{\prime}}^{\prime}\right)_{E} \notin \mathscr{G}(E)$. Thus $x^{\prime} \notin g\left(e^{\prime}\right)$, a contradiction. Hence $\mathscr{L}(E) \subseteq \mathscr{K}(E)$.

Therefore, $\widetilde{U}-\underline{a p r}_{P}\left(\widetilde{U}-g_{E}\right) \widetilde{\subset} \overline{a p r}_{P}\left(g_{E}\right)$.

Conversely, to prove $k_{E} \widetilde{\subset} l_{E}=\widetilde{U}-q_{E}$, by Remark 2.11, it suffices to show $k_{E} \widetilde{\cap} q_{E}=\widetilde{\emptyset}$.

Suppose $w_{E}=k_{E} \widetilde{\cap} q_{E} \neq \widetilde{\emptyset}$. By Proposition 3.5, $\mathscr{W}(E)=\mathscr{K}(E) \cap \mathscr{Q}(E)$. Pick $\left(x_{e}\right)_{E} \in \mathscr{W}(E)$. Then $\left(x_{e}\right)_{E} \in \mathscr{K}(E)$ and $\left(x_{e}\right)_{E} \in \mathscr{Q}(E)$. By Lemma 5.3, $\left(x_{e}\right)_{E} \in P^{g}\left(f_{E}, R\right)$ and $\left(x_{e}\right)_{E} \in P_{h}\left(f_{E}, R\right)$. Thus $R^{*}\left(\left(x_{e}\right)_{E}\right) \cap \mathscr{G}(E) \neq \emptyset$ and $R^{*}\left(\left(x_{e}\right)_{E}\right) \subseteq \mathscr{H}(E)$. Pick $\left(x_{e^{\prime}}^{\prime}\right)_{E} \in R^{*}\left(\left(x_{e}\right)_{E}\right) \cap \mathscr{G}(E)$. Then $\left(x_{e^{\prime}}^{\prime}\right)_{E} \in \mathscr{G}(E)$. Thus $x^{\prime} \in g\left(e^{\prime}\right)$. But $\left(x_{e^{\prime}}^{\prime}\right)_{E} \in R^{*}\left(\left(x_{e}\right)_{E}\right)$. This implies $\left(x_{e^{\prime}}^{\prime}\right)_{E} \in \mathscr{H}(E)$. Thus $x^{\prime} \in h\left(e^{\prime}\right)=U-g\left(e^{\prime}\right)$ and so $x^{\prime} \notin g\left(e^{\prime}\right)$, a contradiction. Hence $\overline{a p r}_{P}\left(g_{E}\right) \widetilde{\subset} \widetilde{U}-$ $\operatorname{apr}_{P}\left(\widetilde{U}-g_{E}\right)$.

Therefore, $\overline{\operatorname{apr}}_{P}\left(g_{E}\right)=\widetilde{U}-\underline{a p r}_{P}\left(\widetilde{U}-g_{E}\right)$.

Corollary 6.2 Let $R$ be a s-relation on $\widetilde{U}$. Then the following are equivalent.

(1) $R$ is serial;

(2) $\forall g_{E} \in S(U, E), \underline{a p r}_{P}\left(g_{E}\right) \widetilde{\subset} \overline{a p r}_{P}\left(g_{E}\right)$;

(3) $\underline{\operatorname{apr}}_{P}(\widetilde{\emptyset})=\widetilde{\emptyset}$

(4) $\overline{\overline{a p r}}_{P}(\widetilde{U})=\widetilde{U}$.

Proof. This follows from Proposition 5.7 and Proposition 6.1.

Corollary 6.3 Let $R$ be a s-relation on $\widetilde{U}$. Then the following are equivalent.

(1) $R$ is reflexive;

(2) $\forall g_{E} \in S(U, E), \underline{a p r}_{P}\left(g_{E}\right) \widetilde{\subset} g_{E}$;

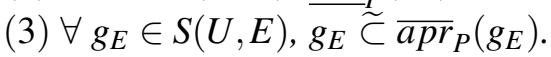

Proof. This follows from Proposition 5.8 and Proposition 6.1.

Corollary 6.4 Let $R$ be a s-relation on $\widetilde{U}$. Then the following are equivalent.

(1) $R$ is symmetric;

(2) $\forall g_{E} \in S_{f}(U, E), g_{E} \widetilde{\subset} \underset{a p r}{P}\left(\overline{a p r}_{P}\left(g_{E}\right)\right)$;

(3) $\forall g_{E} \in S_{f}(U, E), \overline{\operatorname{apr}}_{P}\left(\underline{\operatorname{apr}}_{P}\left(g_{E}\right)\right) \widetilde{\subset} g_{E}$. 
Proof. This follows from Proposition 5.10 and Proposition 6.1.

Corollary 6.5 Let $R$ be a s-relation on $\widetilde{U}$. Then the following are equivalent.

(1) $R$ is transitive;

(2) $\left.\underset{\operatorname{apr}}{P}\left(g_{E}\right) \widetilde{\sim a p r} \underline{a p r}_{P}\left(\underline{a p r}_{P}\right)\right) \quad \forall g_{E} \in$ $S_{f}(U, E)$

(3) $\overline{a p r}_{P}\left(\overline{a p r}_{P}\left(g_{E}\right)\right) \quad \widetilde{C} \overline{a p r}_{P}\left(g_{E}\right) \quad \forall g_{E} \in$ $S_{f}(U, E)$.

Proof. This follows from Proposition 5.12 and Proposition 6.1.

Corollary 6.6 Let $R$ be a s-relation on $\widetilde{U}$. Then the following are equivalent.

(1) $R$ is Euclidean;

(2) $\forall g_{E} \in S_{f}(U, E), \overline{\operatorname{apr}}_{P}\left(g_{E}\right) \widetilde{\widetilde{a p r}} \underline{a p}_{P}\left(\overline{a p r}_{P}\left(g_{E}\right)\right)$;

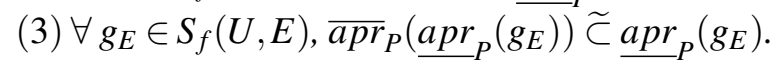

Proof. This follows from Proposition 5.13 and Proposition 6.1.

\subsection{Soft topologies induced by relations on $\widetilde{U}$}

Theorem 6.7 Let $R$ be reflexive on $\widetilde{U}$. Then $\tau_{R}=$ $\left\{g_{E} \in S(U, E): \underline{a p r_{P}}\left(g_{E}\right)=g_{E}\right\}$ is a soft topology over $U$.

Proof. (1) By Proposition 5.9, $\widetilde{\emptyset}, \widetilde{U} \in \tau_{R}$.

(2) Let $g_{E}, h_{E} \in \tau_{R}$. Since $g_{E}=\underset{a p r_{P}}{ }\left(g_{E}\right)$ and $h_{E}=\operatorname{apr}_{P}\left(h_{E}\right)$, by Proposition 5.6, $g_{E} \widetilde{\cap} h_{E}=$ $\operatorname{apr}_{P}\left(g_{E}\right) \widetilde{\cap} \underset{\operatorname{apr}}{P}\left(h_{E}\right)=\underline{a p r}_{P}\left(g_{E} \widetilde{\cap} h_{E}\right)$.

(3) Let $\left(g_{\alpha}\right)_{E} \in \widehat{\tau_{R}} \forall \alpha \in \Lambda$, we will show that $\widetilde{U}\left\{\left(g_{\alpha}\right)_{E}: \alpha \in \Lambda\right\}=\operatorname{apr}_{P}\left(\widetilde{\cup}\left\{\left(g_{\alpha}\right)_{E}\right.\right.$ : $\alpha \in \Lambda\})$. Since $R$ is reflexive, by Proposition 5.8, $\operatorname{apr}_{P}\left(\widetilde{\cup}\left\{\left(g_{\alpha}\right)_{E}: \alpha \in \Lambda\right\}\right) \widetilde{\subset} \widetilde{\cup}\left\{\left(g_{\alpha}\right)_{E}: \alpha \in \Lambda\right\}$.

Conversely, since $\left(g_{\alpha}\right)_{E}=\operatorname{apr}_{P}\left(\left(g_{\alpha}\right)_{E}\right)$, by Proposition 5.6, we have $\widetilde{\cup}\left\{\left(g_{\alpha}\right)_{E}: \alpha \in \Lambda\right\}=$ $\widetilde{\cup}\left\{\underline{a p r}_{P}\left(\left(g_{\alpha}\right)_{E}\right): \alpha \in \Lambda\right\} \widetilde{\subset} \underline{a p r}_{P}\left(\widetilde{\cup}\left\{\left(g_{\alpha}\right)_{E}:\right.\right.$ $\alpha \in \overline{\Lambda\}})$.

Therefore, $\tau_{R}=\left\{g_{E} \in S_{f}(U, E): \operatorname{apr}_{P}\left(g_{E}\right)=\right.$ $\left.g_{E}\right\}$ is a soft topology on $f_{E}$.
Definition 6.8 Let $R$ be reflexive on $\widetilde{U}$. Then $\tau_{R}$ is called the soft topology induced by $R$ on $\widetilde{U}$.

The following Theorem 6.9 gives the structure of the soft topology induced by a reflexive $s$-relation on $\widetilde{U}$.

Theorem 6.9 Let $R$ be reflexive on $\widetilde{U}$ and $\tau_{R}$ the soft topology induced by $R$ on $U$. Then

(1) a) $\tau_{R}=\left\{\underline{a p r}_{P}\left(g_{E}\right): g_{E} \in S(U, E)\right\}$ whenever $R$ is transitive.

b) $\left\{\overline{\operatorname{apr}}_{P}\left(g_{E}\right): g_{E} \in S(U, E)\right\} \subseteq \tau_{R}$ whenever $R$ is Euclidean.

(2) apr $_{P}$ is a soft interior operator of $\tau_{R}$.

(3) $\overline{\overline{a p r}}_{P}$ is a soft closure operator of $\tau_{R}$.

Proof. (1) $a)$ Let $g_{E} \in S(U, E)$. By Corollary 6.5, $\underline{\operatorname{apr}}_{P}\left(\underline{\operatorname{apr}}_{P}\left(g_{E}\right)\right)=\underset{\operatorname{apr}_{P}}{ }\left(g_{E}\right)$. This implies $\operatorname{apr}_{P}\left(g_{E}\right) \overline{\in \tau_{R}}$. Thus $\tau_{R} \supseteq\left\{\underline{a p r}_{P}\left(g_{E}\right): g_{E} \in\right.$

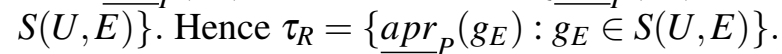

$b)$ By Corollary 6.6, $\left\{\overline{a p r}_{P}\left(g_{E}\right): g_{E} \in\right.$ $S(U, E)\} \subseteq \tau_{R}$.

(2) It suffices to show $\operatorname{apr}_{P}\left(g_{E}\right)=$ $\operatorname{int}\left(g_{E}\right)$ for any $g_{E} \in S(U, E)$.

By (1), ${\underset{a p r}{P}}_{P}\left(g_{E}\right) \in \tau_{R}$. By Corollary 6.3, $\operatorname{apr}_{P}\left(g_{E}\right) \widetilde{\subset} \bar{g}_{E}$. Thus $\operatorname{apr}_{P}\left(g_{E}\right) \widetilde{\subset} \operatorname{int}\left(g_{E}\right)$.

Conversely, suppose $h_{E} \in \tau_{R}$ and $h_{E} \widetilde{\subset} g_{E}$, by Proposition 5.6, $h_{E}=\underline{a p r}_{P}\left(h_{E}\right) \widetilde{\subset} \underline{a p r}_{P}\left(g_{E}\right)$. By Remark 2.5,

$\operatorname{int}\left(g_{E}\right)=\widetilde{\cup}\left\{h_{E}: h_{E} \in \tau_{R}\right.$ and $\left.h_{E} \widetilde{\subset} g_{E}\right\} \widetilde{\subset} \underline{a p r_{P}}\left(g_{E}\right)$.

Thus $\underset{\operatorname{apr}}{\operatorname{Pa}}\left(g_{E}\right)=\operatorname{int}\left(g_{E}\right)$.

(3) By Proposition 2.17 and Proposition 6.1,

$\overline{\operatorname{apr}}_{P}\left(g_{E}\right)=\widetilde{U}-\underline{a p r}_{P}\left(\widetilde{U}-g_{E}\right)=\widetilde{U}-\operatorname{int}(\widetilde{U}-$ $\left.g_{E}\right)=\operatorname{cl}\left(g_{E}\right)$.

Theorem 6.10 Let $R$ be reflexive and transitive on $\widetilde{U}$ and $\tau_{R}$ the soft topology induced by $R$ on $\widetilde{U}$. Then $\forall g_{E} \in S(U, E), g_{E} \in \tau_{R} \Leftrightarrow g_{E} \in \tau_{R}^{\prime}$.

Proof. Necessity. Let $g_{E} \in \tau_{R}$. Then $\operatorname{apr}_{P}\left(g_{E}\right)=$ $g_{E}$. By Proposition 6.1 and Remark 2.9, $\overline{\overline{a p r}}_{P}\left(g_{E}^{\prime}\right)=$ $\widetilde{U}-\operatorname{apr}_{P}\left(\left(g_{E}^{\prime}\right)^{\prime}\right)=\widetilde{U}-\operatorname{apr}_{P}\left(g_{E}\right)=\widetilde{U}-g_{E}=g_{E}^{\prime}$. By Theorem 6.9, $g_{E}^{\prime}=\overline{\operatorname{apr}_{P}}\left(g_{E}^{\prime}\right) \in \tau_{R}$. Thus $g_{E} \in \tau_{R}^{\prime}$. 
Sufficiency. Let $g_{E} \in \tau_{R}^{\prime}$. Then $g_{E}^{\prime} \in \tau_{R}$ and $\operatorname{apr}_{P}\left(g_{E}^{\prime}\right)=g_{E}^{\prime}$. By Proposition 6.1 and Remark 2.9, $\overline{\operatorname{apr}}_{P}\left(g_{E}\right)=\widetilde{U}-\underline{a p r}_{P}\left(g_{E}^{\prime}\right)=g_{E}$. By Theorem 6.5, $g_{E}=\overline{a p r}_{P}\left(g_{E}\right) \in \overline{\tau_{R}}$.

Definition 6.11 Let $\tau$ be a topology on $U . \quad \tau$ is called a pseudo-discrete topology on $U$, if $A \subseteq U$ is open in $U$ if and only if $A$ is closed in $U$.

Theorem 6.12 Let $R$ be reflexive and transitive on $\widetilde{U}$. Then $\tau_{R}$ is a pseudo-discrete topology over $U$.

Proof. This holds by Theorem 6.7 and Theorem 6.10.

\section{Conclusions}

In this paper, the fact that soft sets can be translated into soft point sets has been proved. Thus, we may expediently handled soft set like ordinary sets. We have proposed $s$-relations on soft sets. By means of soft points and $s$-relations, a pair of soft rough approximate operations has been defined. Serial, reflexive, symmetric, transitive and Euclidean $s$-relations have been characterized by using soft rough approximate operations. In addition, we have investigated soft topologies induced by a reflexive $s$-relation on a special soft set and given their structure. In the future, we will investigate the axiomatization of the proposed soft rough approximate operations and consider some concrete applications of our proposed notions.

\section{Acknowledgements}

The authors would like to thank the editors and the anonymous reviewers for their valuable comments and suggestions which have helped immensely in improving the quality of the paper. This work is supported by Guangxi University Science and Technology Research Project (KY2015YB266), Given Point on Master of Applied Statistics in Guangxi University of Finance and Economics (2016TJYB03), Quantitative Economics Key Laboratory Program of Guangxi University of Finance and Economics (2014SYS11), Guangxi Province Universities and
Colleges Excellence Scholar and Innovation Team Funded Scheme, and National Natural Science Foundation of China (11461005).

\section{References}

1. A.Aygünoğlu, H.Aygün, "Introduction to fuzzy soft groups," Comput. Math. Appl., 58, 1279-1286 (2009).

2. H.Aktas, N.Cağman, "Soft sets and soft groups," Inform. Sci., 177, 2726-2735 (2007).

3. M.I.Ali, F.Feng, X.Liu, W.K.Min, M.Shabir, "On some new operations in soft set theory," Comput. Math. Appl., 57, 1547-1553 (2009).

4. M.I.Ali, M.Shabir, M.Naz, "Algebraic structures of soft sets associated with new operations," Comput. Math. Appl., 61, 2647-2654 (2011).

5. K.V.Babitha, J.J.Sunil, "Soft set relations and functions," Comput. Math. Appl., 60, 1840-1849 (2010).

6. F.Feng, C.Li, B.Davvaz, M.I.Ali, "Soft sets combined with fuzzy sets and rough sets: a tentative approach," Soft Comput., 14, 899-911 (2010).

7. F.Feng, X.Liu, V.Leoreanu-Fotea, Y.B.Jun, "Soft sets and soft rough sets," Inform. Sci., 181, 1125-1137 (2011).

aking," J. Comput. Appl. Math., 234, 10-20 (2010).

8. X.Ge, Z.Li, Y.Ge, "Topological spaces and soft sets," J. Comput. Anal. Appl., 13, 881-885 (2011).

9. S.Hussain, B.Ahmad, "Some properties of soft topological spaces," Comput. Math. Appl., 62, 4058-4067 (2011).

10. Y.Jiang, Y.Tang, Q.Chen, J.Wang, S.Tang, "Extending soft sets with description logics," Comput. Math. Appl., 59, 2087-2096 (2010).

11. Y.Liu, M.Luo, "Fuzzy Topology", World Scientific Publishing, Singapore, 1998.

12. Z.Li, G.Wen, Y.Han, "Decision making based on intuitionistic fuzzy soft sets and its algorithm," J. Comput. Anal. Appl., 17, 620-631 (2014).

13. Z.Li, T.Xie, "Roughness of fuzzy soft sets and related results," Int. J. Comput. Intell. Syst., 8, 278-296 (2015).

14. Z.Li, T.Xie, "The relationship among soft sets, soft rough sets and topologies," Soft Comput., 18, 717-728 (2014).

15. Z.Li, N.Xie, G.Wen, "Soft coverings and their parameter reductions," Appl. Soft Comput., 31, 48-60 (2015).

16. Z.Li, D.Zheng, J.Hao, " $L$-fuzzy soft sets based on complete Boolean lattices," Comput. Math. Appl., 64, 2558-2574 (2012).

17. G.Liu, W.Zhu, "The algebraic structures of generalized rough sets," Inform. Sci., 178, 4105-4113 (2008).

18. P.K.Maji, R.Biswas, A.R.Roy, "Soft set theory," Comput. Math. Appl., 45, 555-562 (2003).

19. P.K.Maji, R.Biswas, A.R.Roy, "Fuzzy soft sets," $J$. 
Fuzzy Math., 9, 589-602 (2001).

20. P.K.Maji, A.R.Roy, "An application of soft sets in a decision making problem," Comput. Math. Appl., 44, 1077-1083 (2002).

21. D.Molodtsov, "Soft set theory-first result," Comput. Math. Appl., 37, 19-31 (1999).

22. Z.Pawlak, "Rough sets: Theoretical sspects of reasoning about data", Kluwer Academic Publishers, Boston, 1991.

23. B.Pu, Y.Liu, "Fuzzy Topology I. Neighborhood structure of a fuzzy point and Moore-Smith convergence," J. Math. Anal. Appl., 76, 571-599 (1980).

24. A.R.Roy, P.K.Maji, "A fuzzy soft set theoretic approach to decision making problems," J. Comput. Appl. Math., 2003, 412-418 (2007).

25. M.Shabir, M.Naz, "On soft topological spaces," Com- put. Math. Appl., 61, 1786-1799 (2011).

26. Y.Y.Yao, "Constructive and algebraic methods of the theory of rough sets," Inform. Sci., 109, 21-47 (1998).

27. L.A.Zadeh, "Fuzzy sets," Inform. Control, 8, 338-353 (1965).

28. X.Zhang, J.Dai, Y.Yu, "On the union and intersection operations of rough sets based on various approximation spaces," Inform. Sci., 292, 214-229 (2015).

29. X.Zhang, D.Miao, C.Liu, M.Le, "Constructive methods of rough approximation operators and multigranulation rough sets," Knowl-Based Syst., 91, 114-125 (2016).

30. W.Zhang, W.Wu, J.Liang, D.Li, "Rough set theorey and methods", Chinese Scientific Publishers, Beijing, 2001. 